\title{
Benzophenanthrothiophenes: Syntheses, Crystal Structures and Properties
}

Samala Venkateswarlu, ,a,b Suhendro Purbo Prakoso,, bushil Kumar, ${ }^{\text {a }}$ Ming-Yu Kuo, d,* and YuTai $\mathrm{TaO}^{\mathrm{a}, *}$

Institute of Chemistry, Academia Sinica, Taipei, 115, Taiwan. ${ }^{b}$ Taiwan International Graduate Program, Sustainable Chemical Science and Technology, Academia Sinica, Taipei 115, Taiwan. 'Department of Applied Chemistry, National Chiao Tung University, Hsinchu 300, Taiwan. dDepartment of Applied Chemistry, National Chi Nan University, Nantou, 545, Taiwan.

\begin{tabular}{|c|c|c|}
\hline & Table of Contents & Page \\
\hline 1. & $\begin{array}{l}\text { Proposed reaction mechanisms showing } \\
\text { formation of BPBPT (Scheme S1) }\end{array}$ & $\mathrm{S} 2$ \\
\hline 2. & $\begin{array}{l}\text { NMR spectra of the derivatives }\left({ }^{1} \mathrm{H} \text { and }\right. \\
{ }^{13} \mathrm{C} \text { NMR spectra of the compounds) } \\
\text { (Figures S1-S26) }\end{array}$ & S3-S15 \\
\hline 3. & $\begin{array}{l}\text { High-resolution MALDI-TOF mass spectra } \\
\text { of BPBPTs (Figures S27-S31). }\end{array}$ & S16-S18 \\
\hline \multirow[t]{2}{*}{4.} & $\begin{array}{l}\text { Thermal ellipsoid plots of BPBPTs (Figure } \\
\text { S32) }\end{array}$ & S19-S23 \\
\hline & Table S1. Dipole moments of BPBPTs & S24 \\
\hline 5. & $\begin{array}{l}\text { Normalized absorption and emission } \\
\text { spectra of BPBPTs in dichloromethane } \\
\text { (Figures S33) }\end{array}$ & S25 \\
\hline 6. & $\begin{array}{l}\text { HOMO-LUMO plots of BPBPTs (Figure } \\
\text { S34) }\end{array}$ & S25-26 \\
\hline 7. & $\begin{array}{l}\text { Thermogravimetric plots of BPBPTs } \\
\text { (Figure S35) }\end{array}$ & S26 \\
\hline 8. & $\begin{array}{l}\text { The molecular packings and distances in } \\
\text { neighboring dimers (Dn) (Figure S36) }\end{array}$ & S27 \\
\hline 9. & $\begin{array}{l}\text { Single-crystals field-effect transistor plots } \\
\text { of BPBPT, Flu-BPBPT, Cl-BPBPT and } \\
\text { PFlu-BPBPT (Figure S37)and related } \\
\text { transistor data (Tables S2-S5) }\end{array}$ & S28-S34 \\
\hline 10. & $\begin{array}{l}\text { Single-crystal X-ray data of BPBPT, Me- } \\
\text { BPBPT, Flu-BPBPT, Cl-BPBPT and } \\
\text { PFlu-BPBPT }\end{array}$ & S34-S38 \\
\hline 11. & $\begin{array}{l}\text { Optimized coordinates for BPBPT, Me- } \\
\text { BPBPT, Flu-BPBPT, Cl-BPBPT and } \\
\text { PFlu-BPBPT }\end{array}$ & S38-S48 \\
\hline
\end{tabular}


1. Proposed reaction mechanisms showing formation of BPBPT over BPBPT1

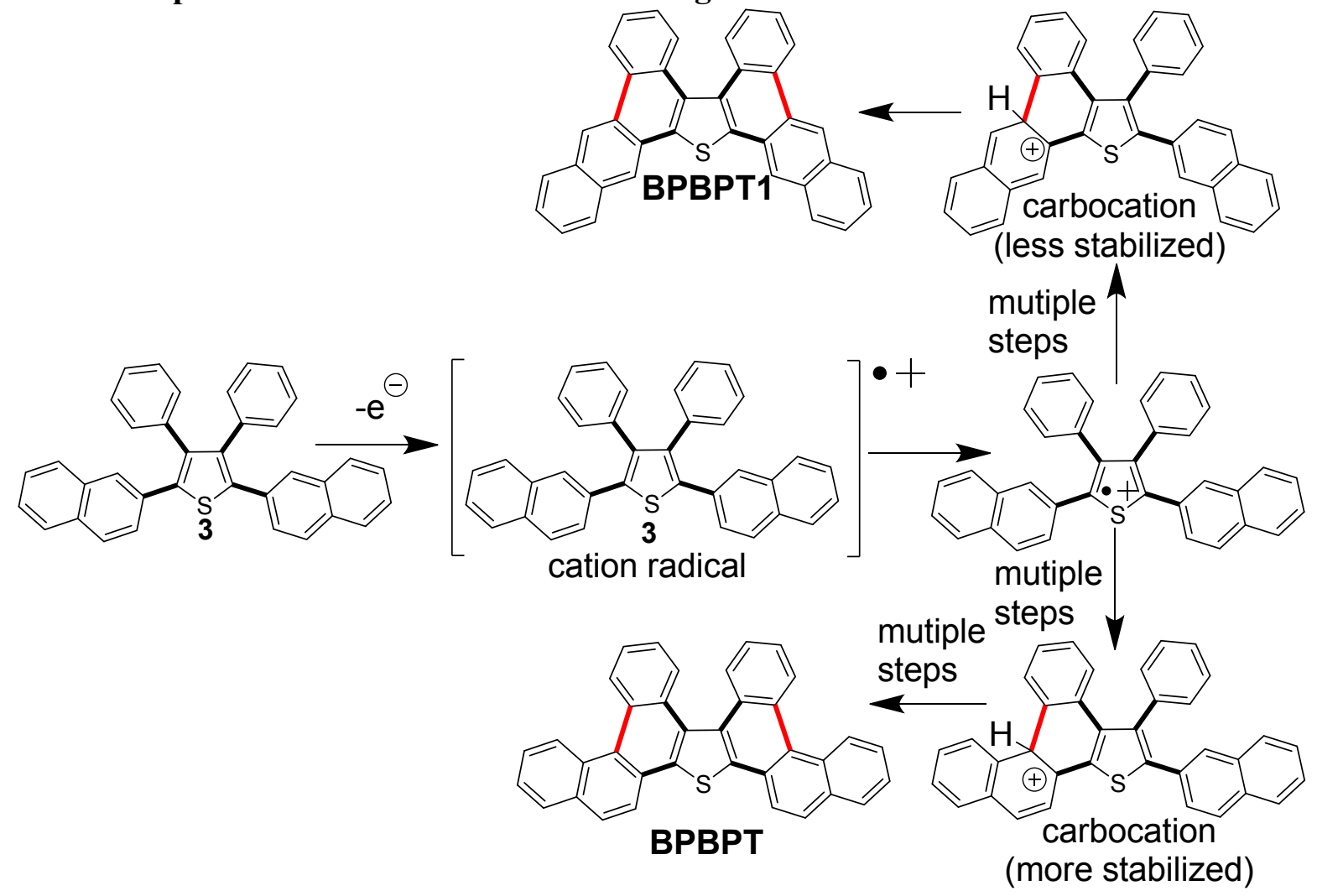

Scheme S1. Suggested mechanism showing the formation of BPBPT and BPBPT1. 


\section{NMR spectra of the derivatives}

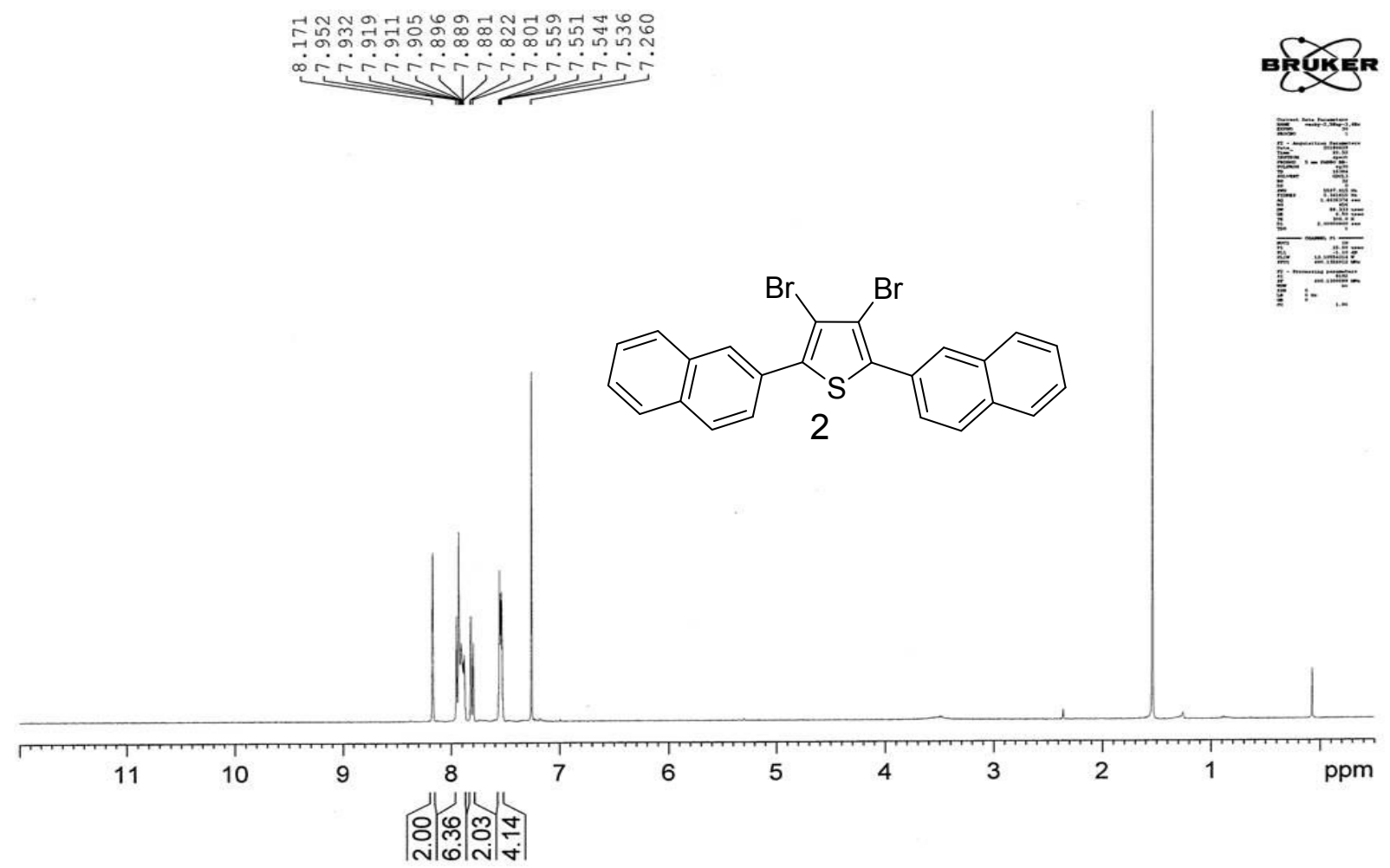

Figure S1. ${ }^{1} \mathrm{H}$ NMR spectrum of 3,4-dibromo-2,5-di(naphthalen-2-yl)thiophene (2)

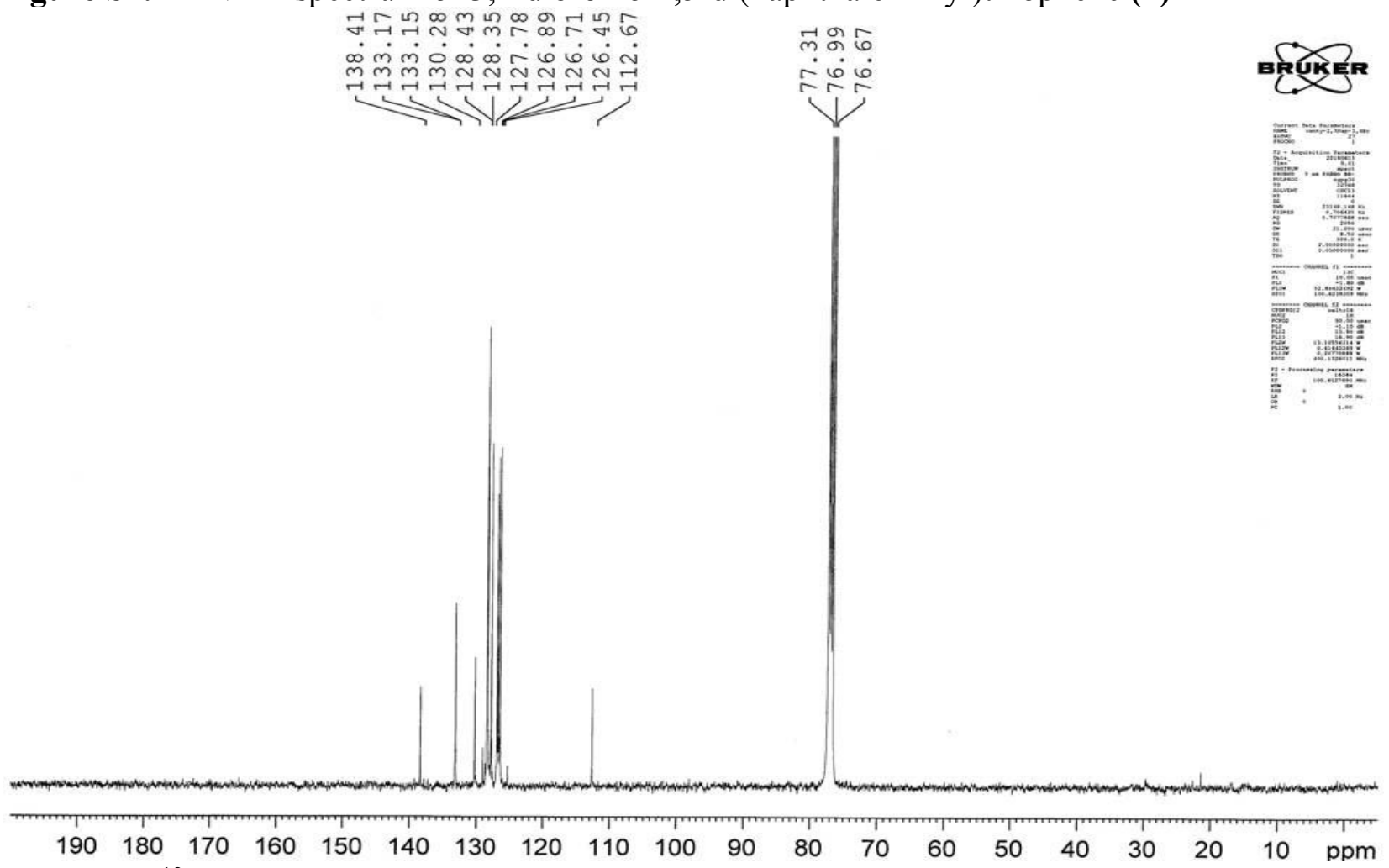

Figure S2. ${ }^{13} \mathrm{C}$ NMR spectrum of 3,4-dibromo-2,5-di(naphthalen-2-yl)thiophene (2) 
<smiles>c1ccc(-c2c(-c3ccc4ccccc4c3)sc(-c3ccc4ccccc4c3)c2-c2ccccc2)cc1</smiles>
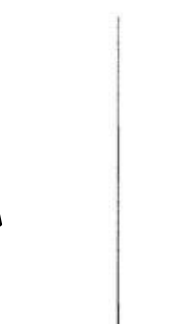

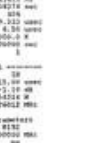




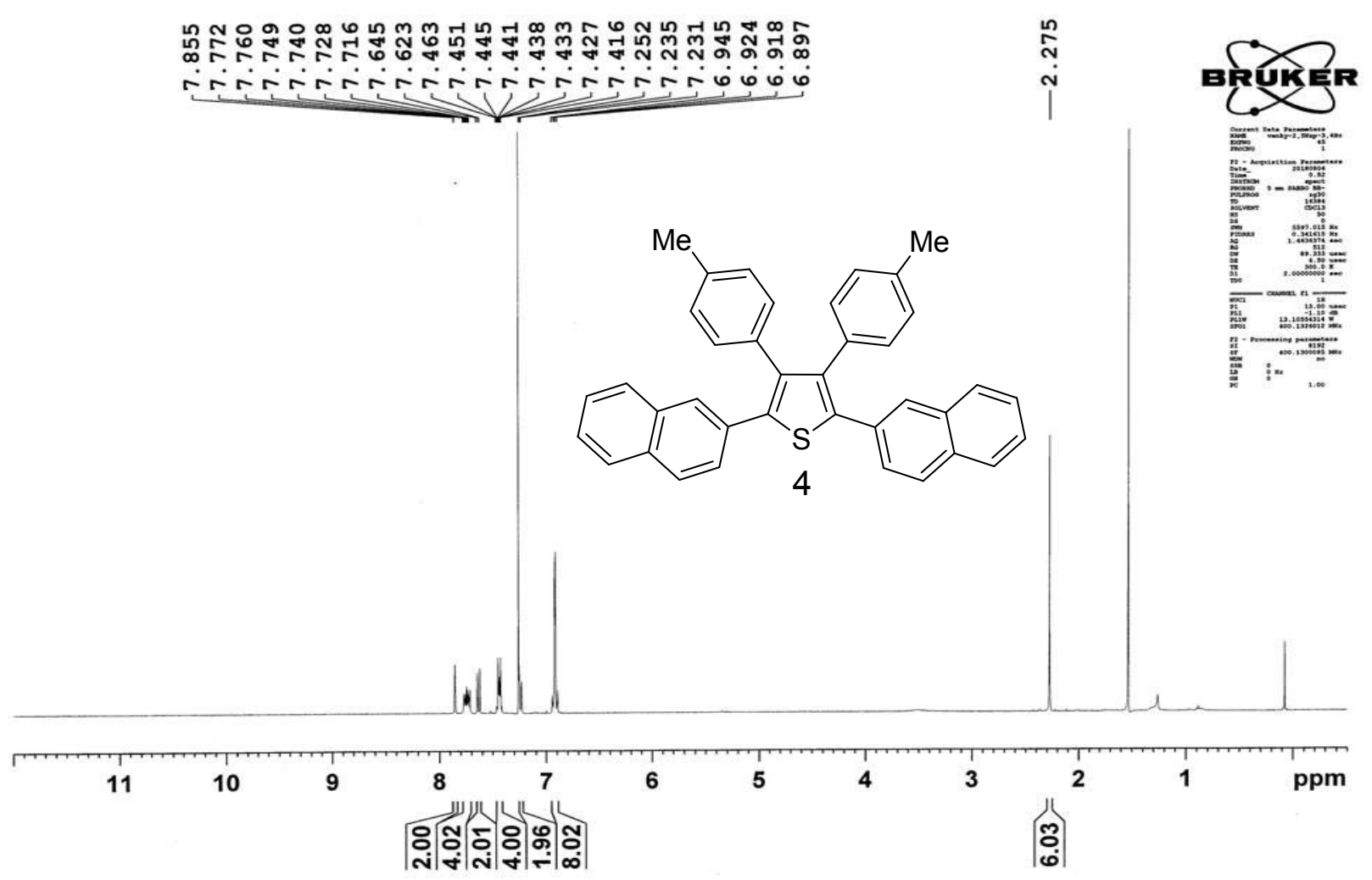

Figure S5. ${ }^{1} \mathrm{H}$ NMR spectrum of 2,5-di(naphthalen-2-yl)-3,4-di-p-tolylthiophene (4)
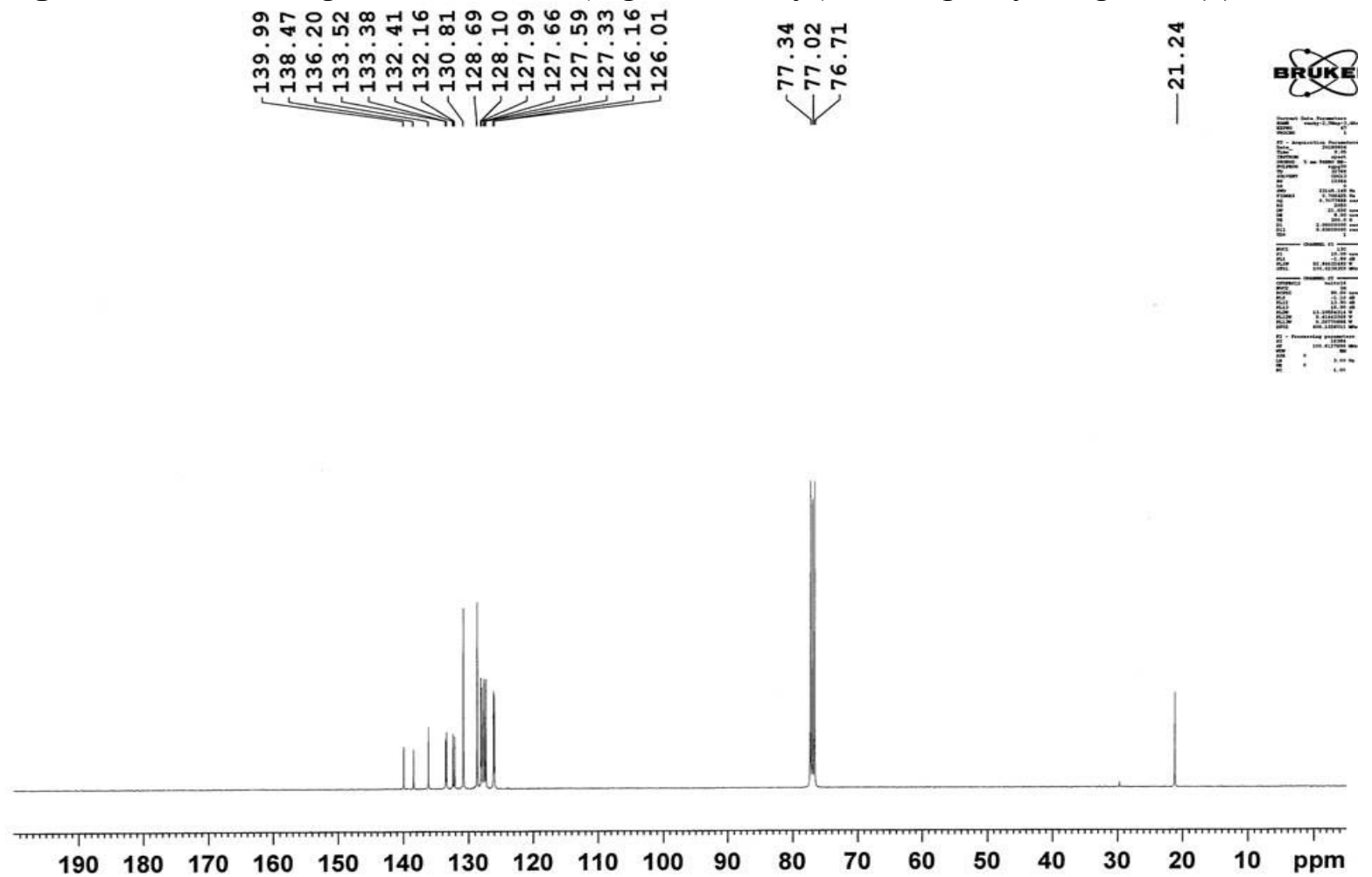

Figure S6. ${ }^{13} \mathrm{C}$ NMR spectrum of 2,5-di(naphthalen-2-yl)-3,4-di-p-tolylthiophene (4) 


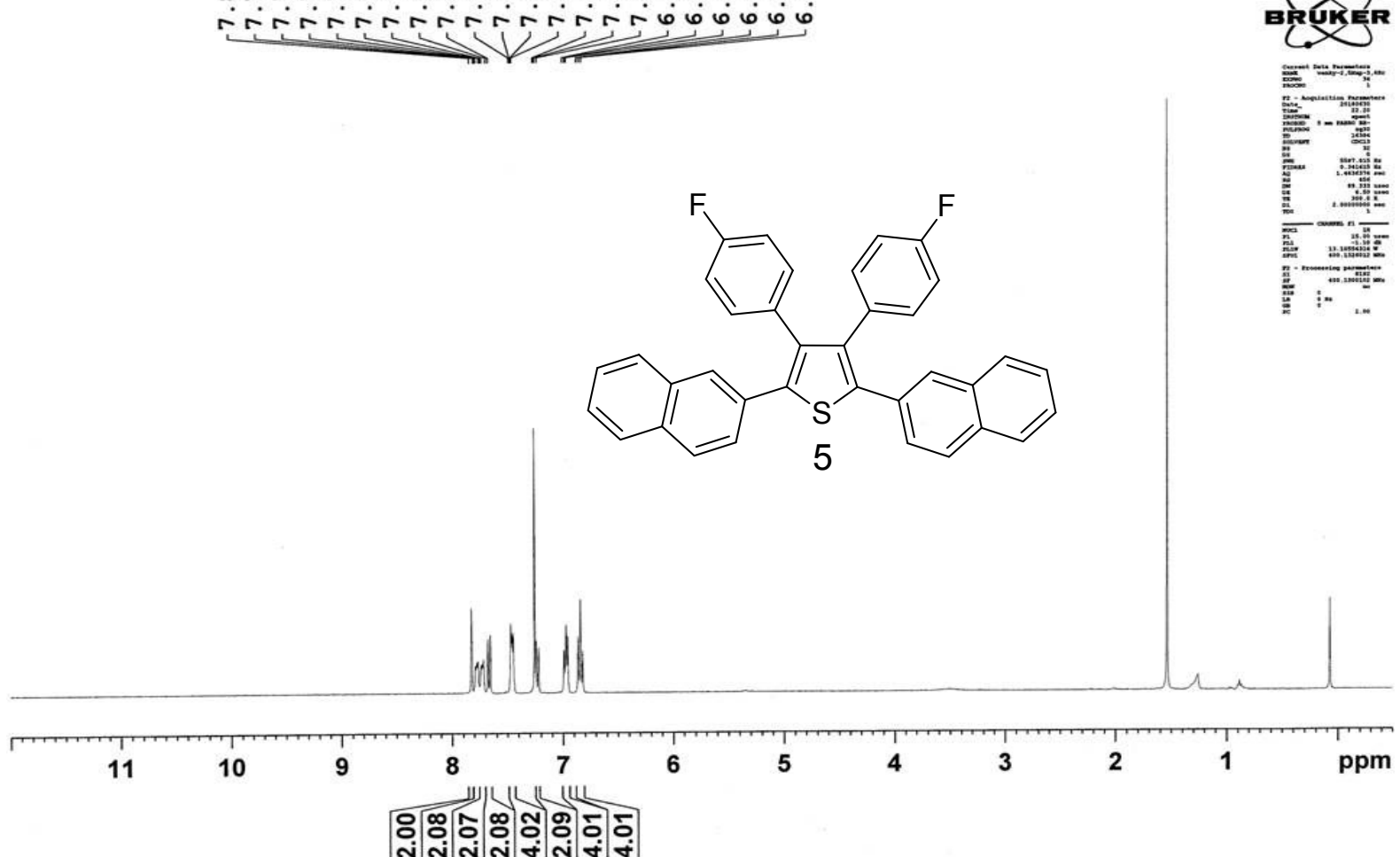

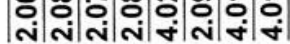

Figure S7. ${ }^{1} \mathrm{H}$ NMR spectrum of 3,4-bis(4-fluorophenyl)-2,5-di(naphthalen-2yl)thiophene (5)

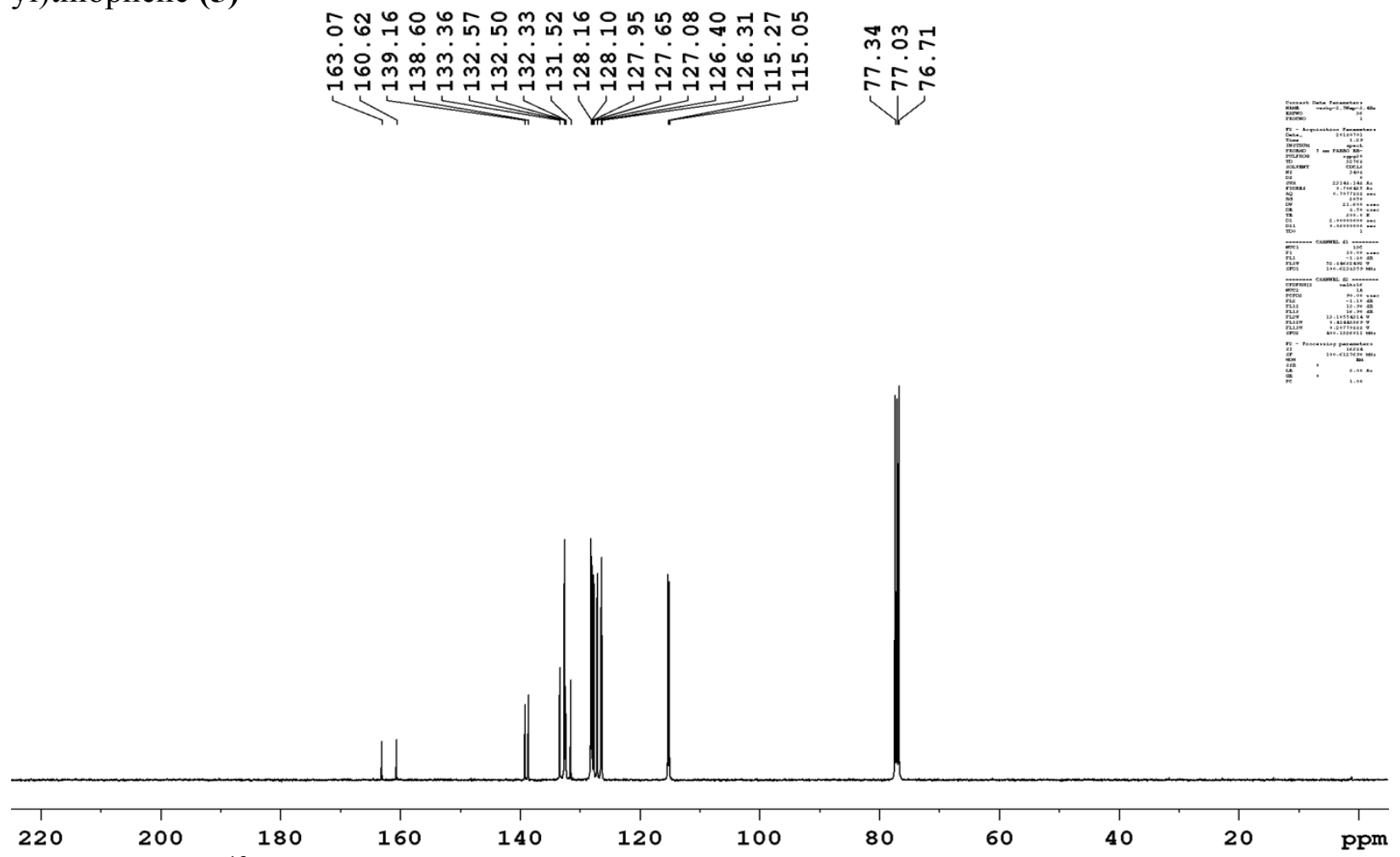

Figure S8. ${ }^{13} \mathrm{C}$ NMR spectrum of 3,4-bis(4-fluorophenyl)-2,5-di(naphthalen-2yl)thiophene (5). 


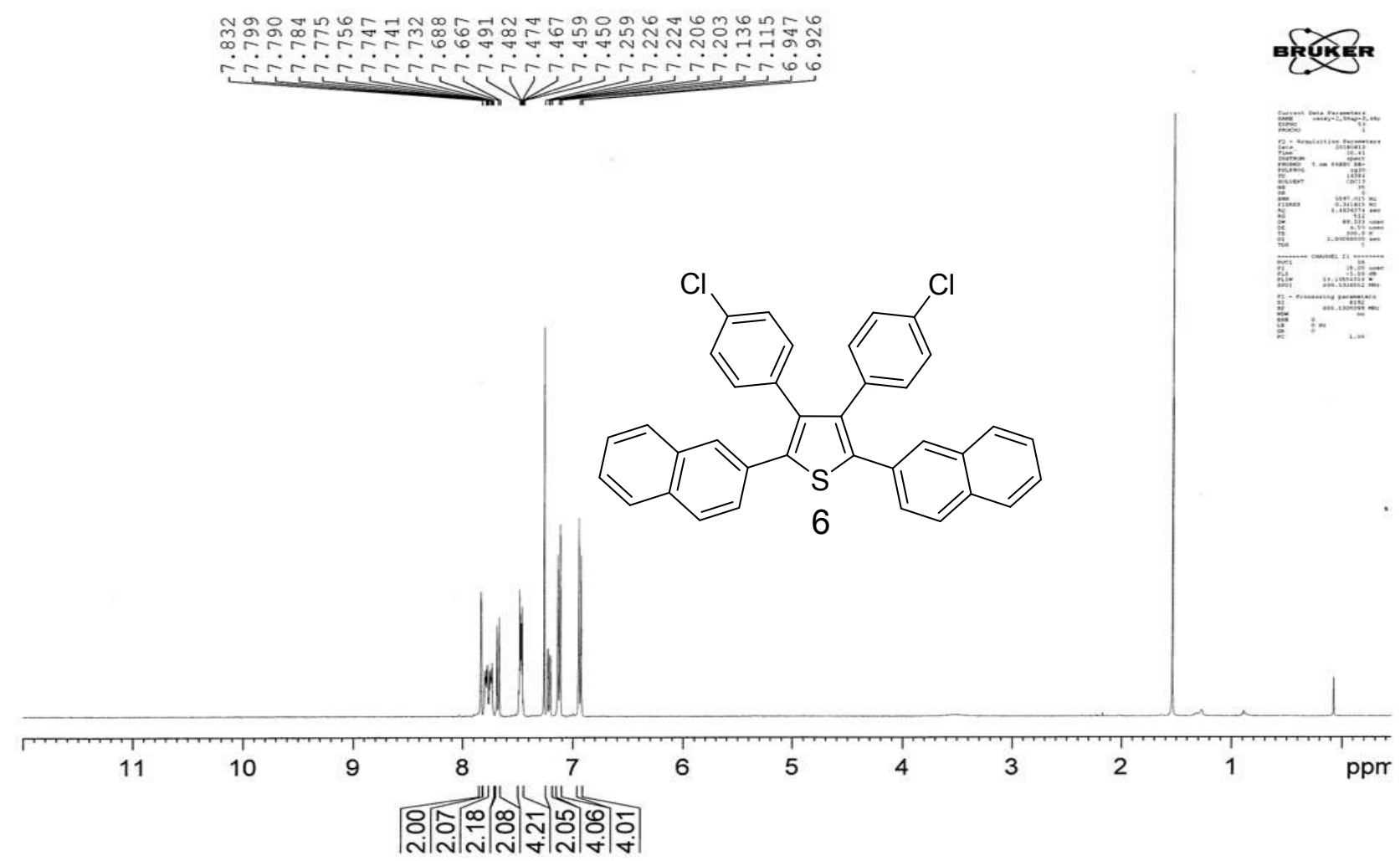

Figure S9. ${ }^{1} \mathrm{H}$ NMR spectrum of 3,4-bis(4-chlorophenyl)-2,5-di(naphthalen-2yl)thiophene (6).
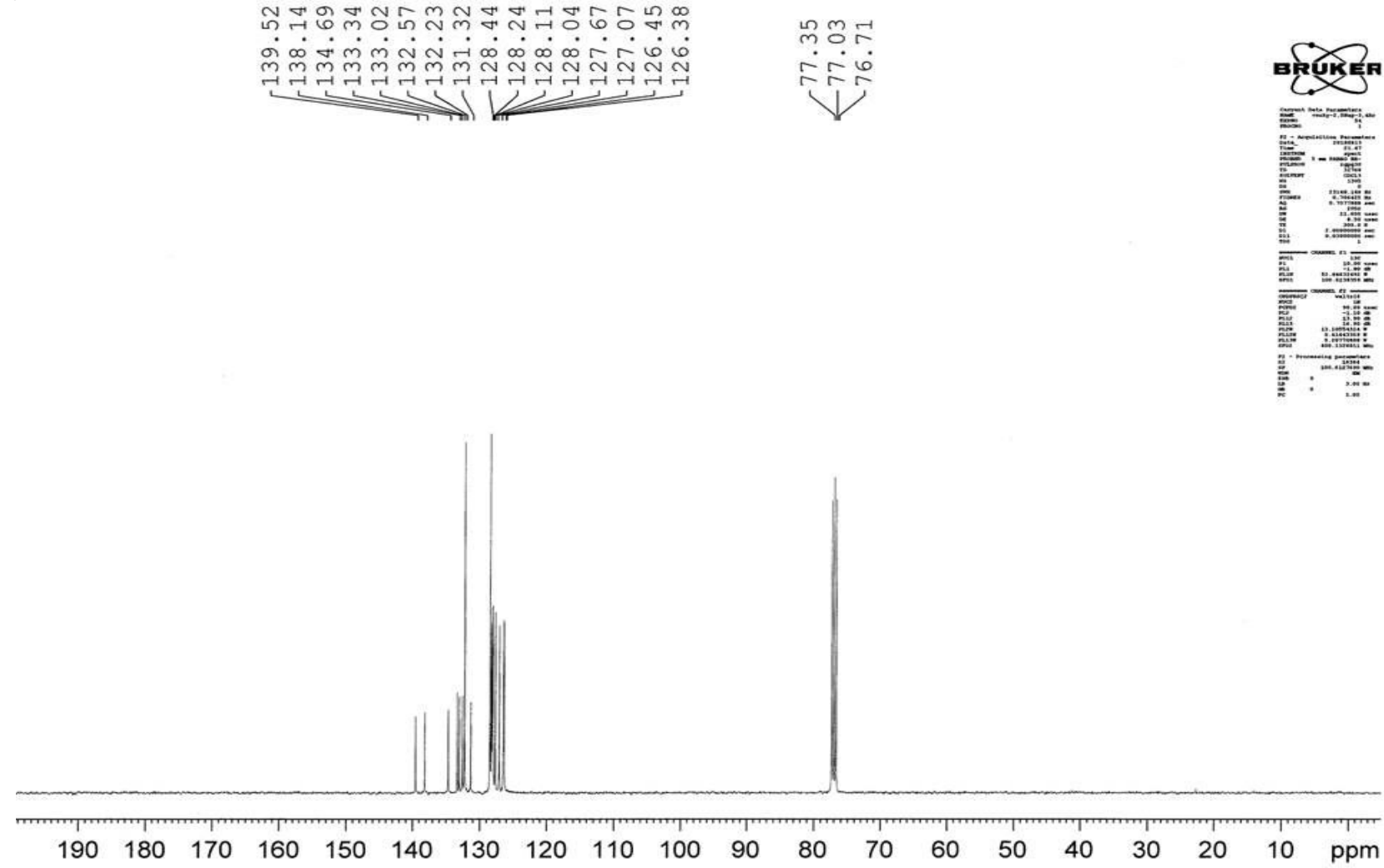

Figure S10. ${ }^{13} \mathrm{C}$ NMR spectrum of 3,4-bis(4-chlorophenyl)-2,5-di(naphthalen-2yl)thiophene (6). 


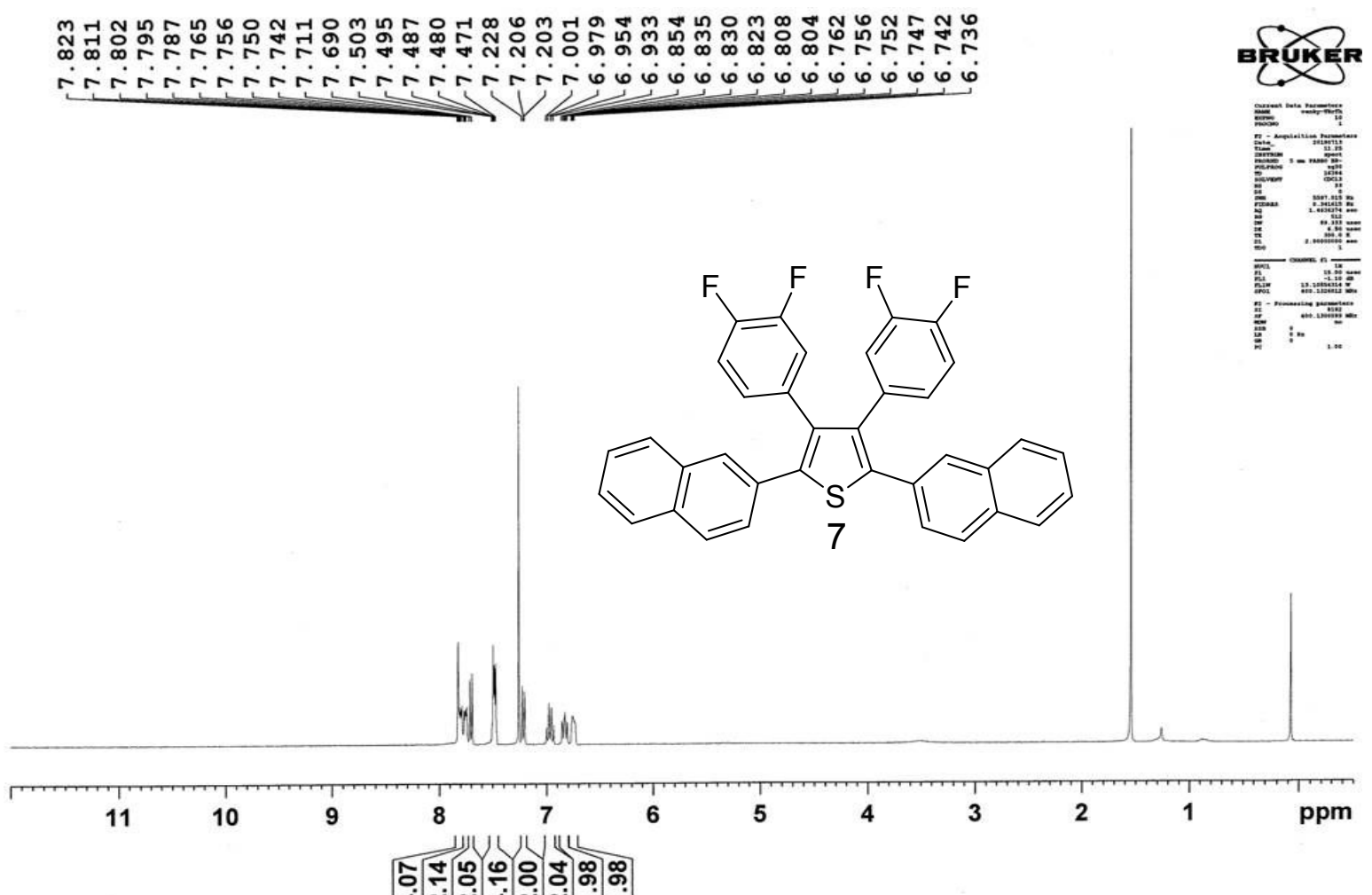

Figure S11. ${ }^{1} \mathrm{H}$ NMR spectrum of 3,4-bis(3,4-difluorophenyl)-2,5-di(naphthalen-2yl)thiophene (7)

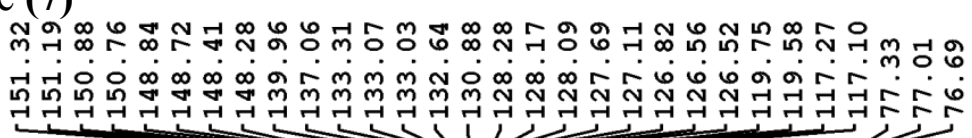

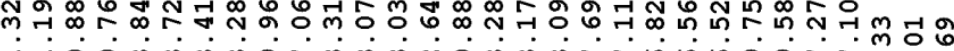

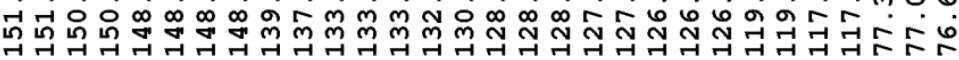

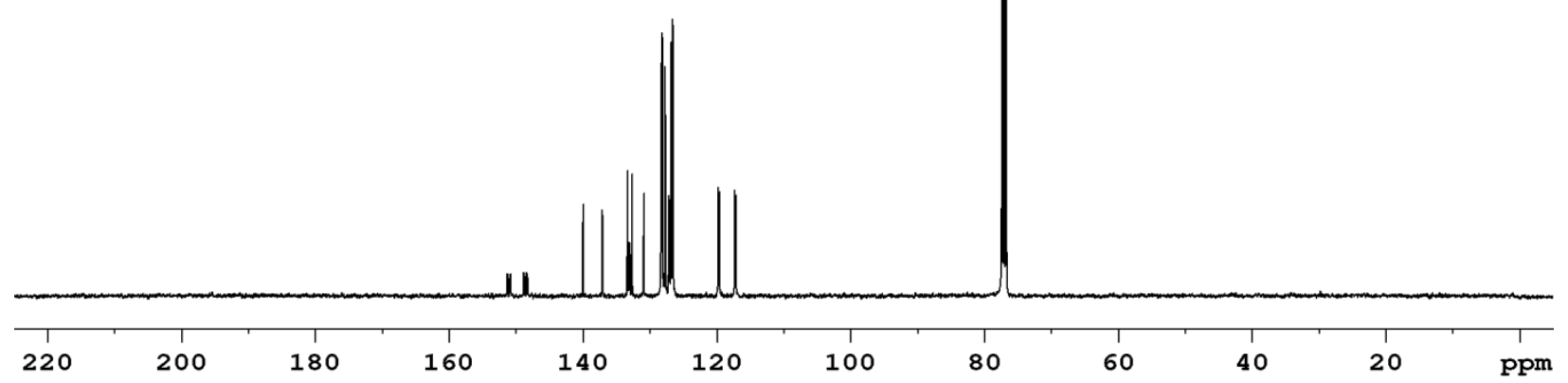

Figure S12. ${ }^{13} \mathrm{C}$ NMR spectrum of 3,4-bis(3,4-difluorophenyl)-2,5-di(naphthalen-2yl)thiophene (7) 


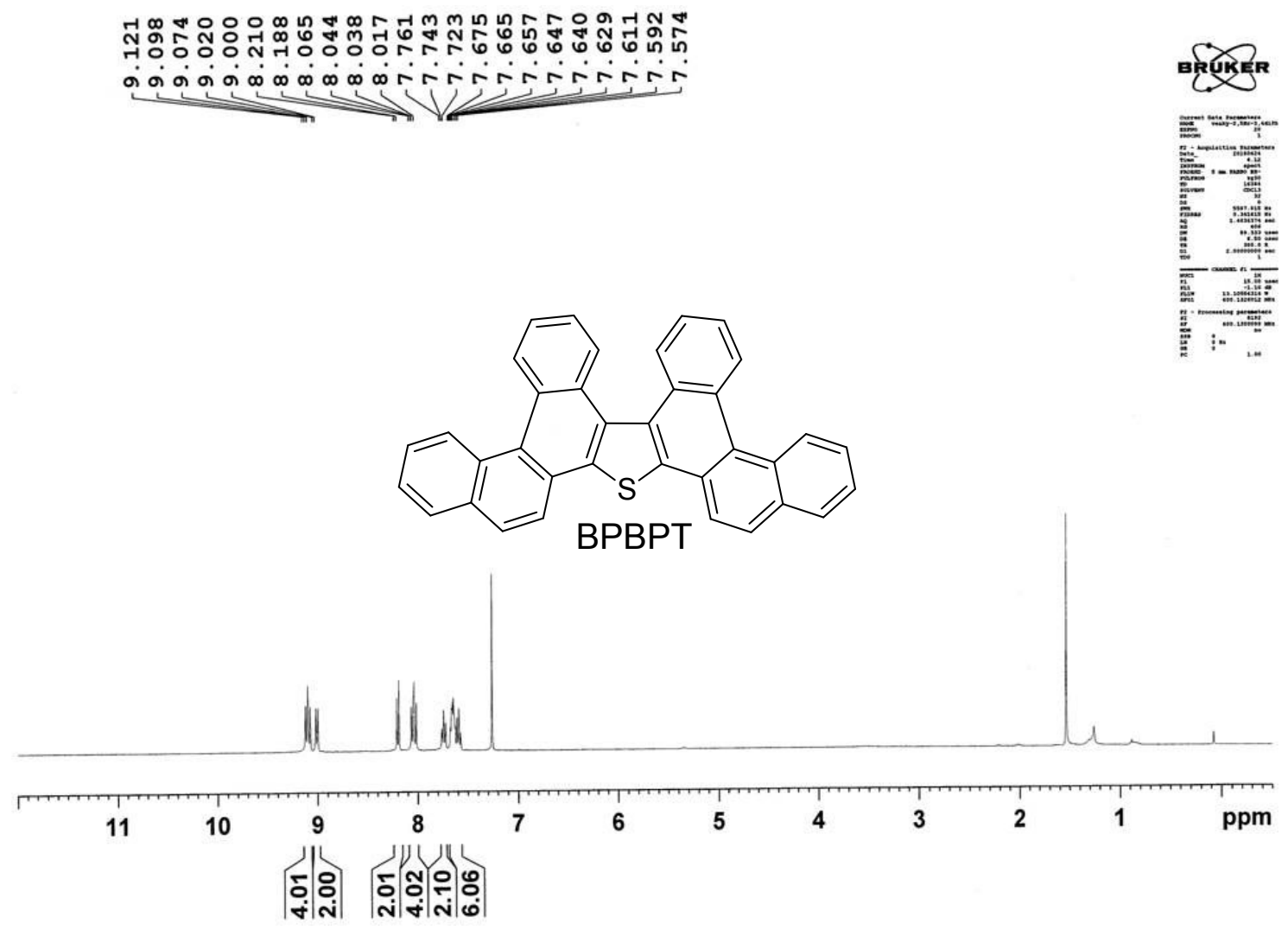

Figure S13. ${ }^{1} \mathrm{H}$ NMR spectrum of benzo[3,4]phenanthro[1,2-b]benzo[3,4]phenanthro[2,1d] thiophene (BPBPT)

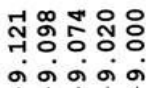

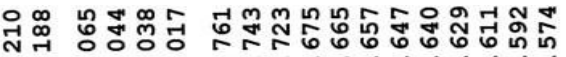

i/

1111

BRिए
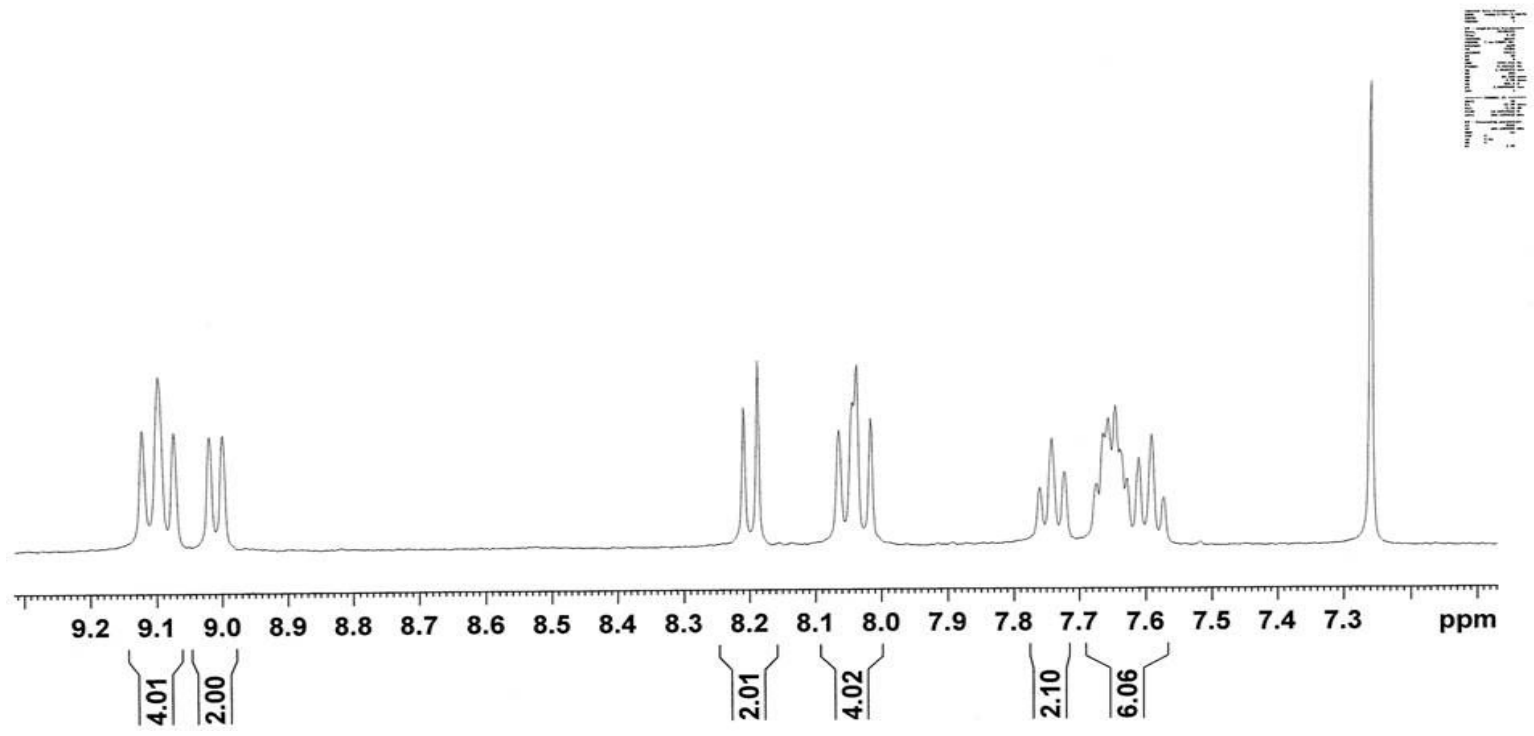

Figure S14. Expanded ${ }^{1} \mathrm{H}$ NMR spectrum of benzo[3,4]phenanthro[1,2$b]$ benzo[3,4]phenanthro[2,1- $d]$ thiophene (BPBPT) 


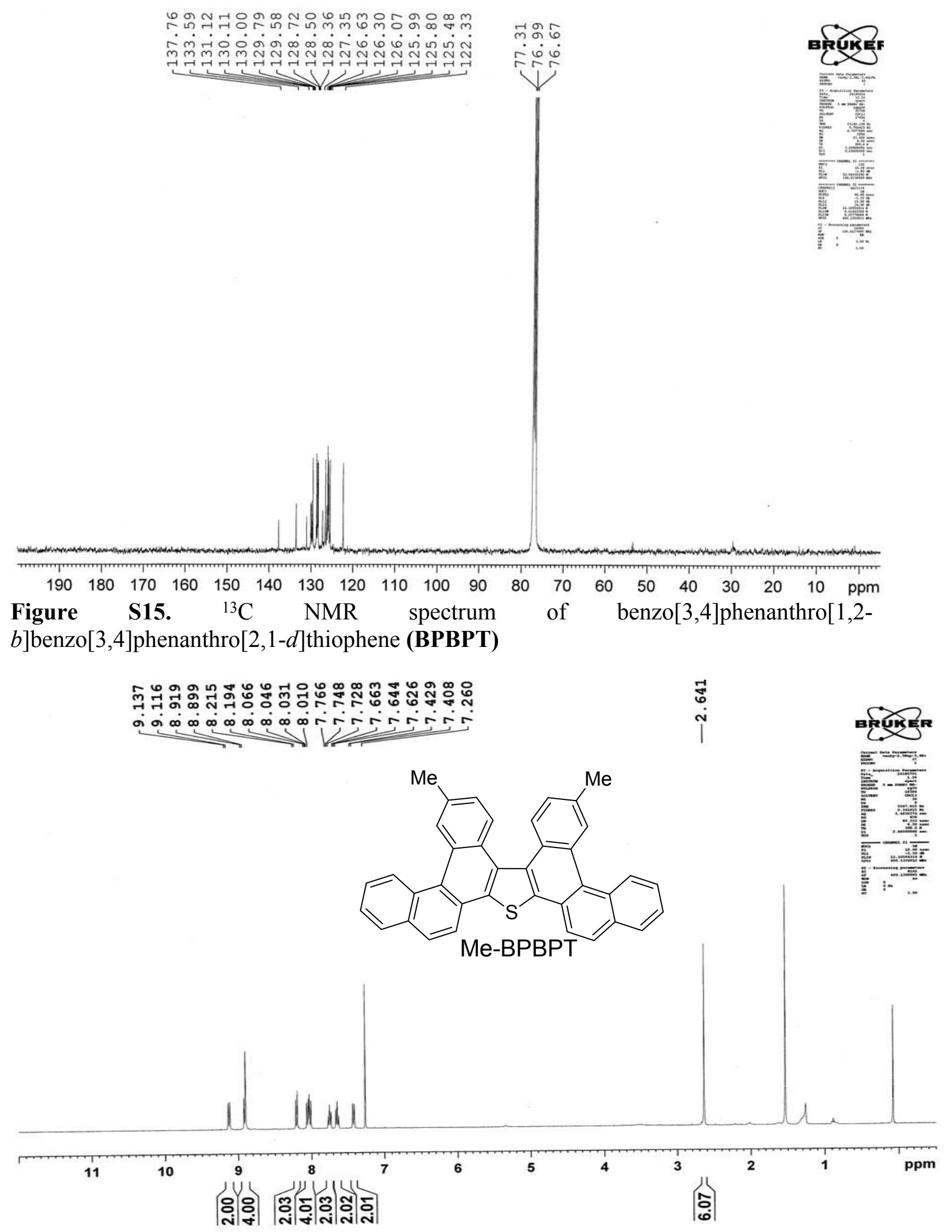

Figure S16. ${ }^{1} \mathrm{H}$ NMR spectrum of 8,13-dimethylbenzo[3,4]phenanthro[1,2$b]$ benzo[3,4]phenanthro[2,1- $d]$ thiophene (Me-BPBPT) 


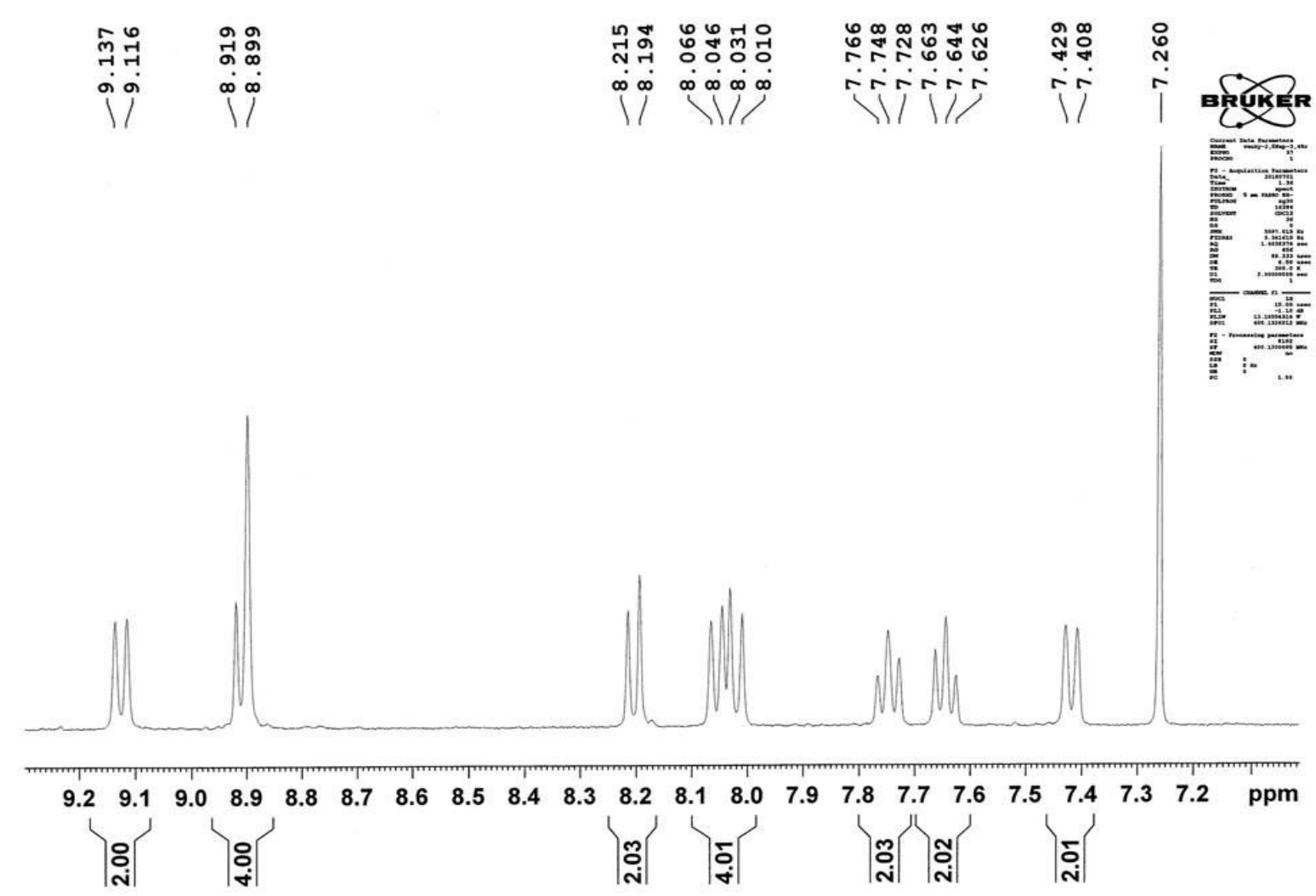

Figure S17. Expanded ${ }^{1} \mathrm{H}$ NMR spectrum of 8,13-dimethylbenzo[3,4]phenanthro[1,2$b]$ benzo[3,4]phenanthro[2,1- $d]$ thiophene (Me-BPBPT)

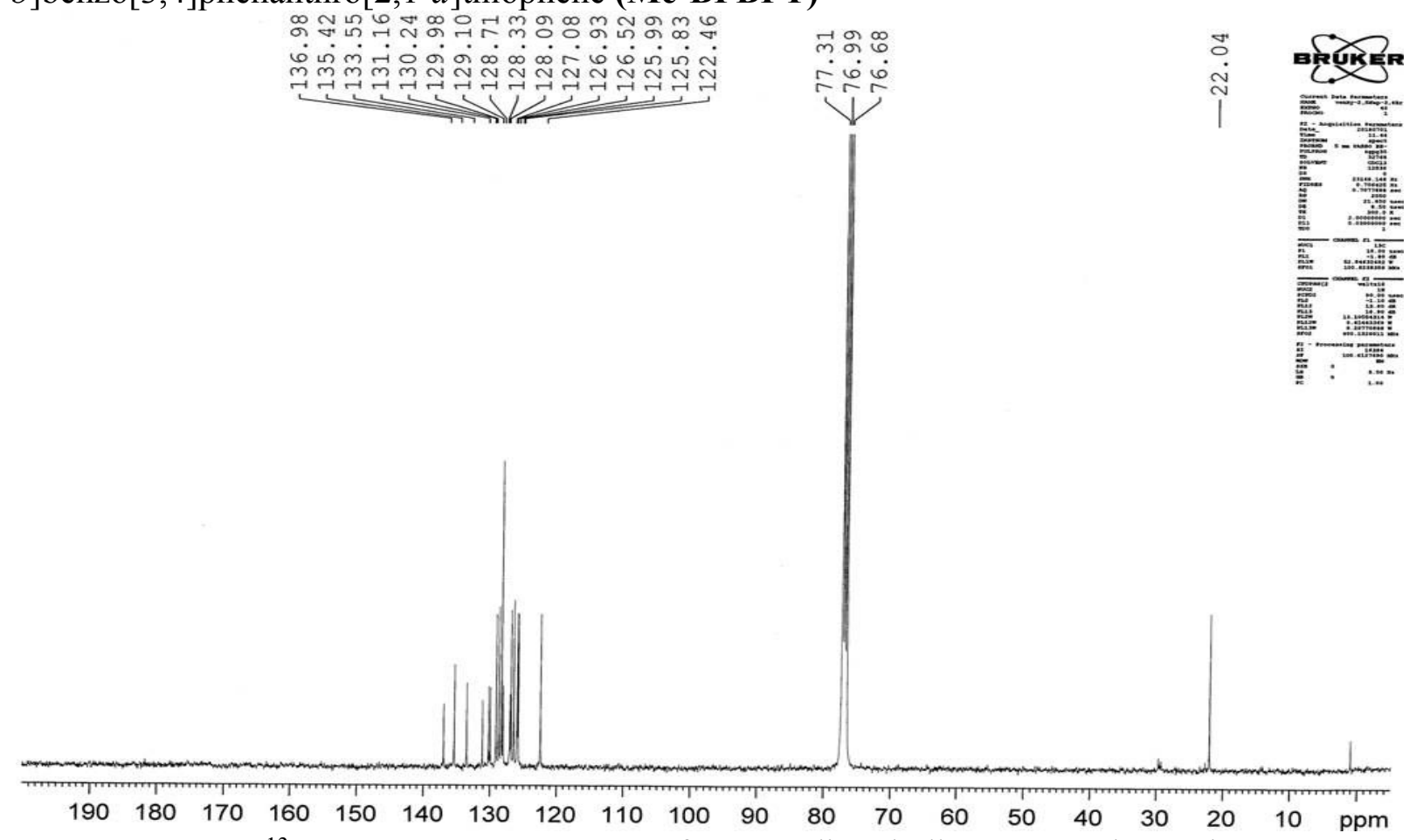

Figure S18. ${ }^{13} \mathrm{C}$ NMR spectrum of 8,13-dimethylbenzo[3,4]phenanthro[1,2$b]$ benzo[3,4]phenanthro[2,1-d] thiophene (Me-BPBPT) 


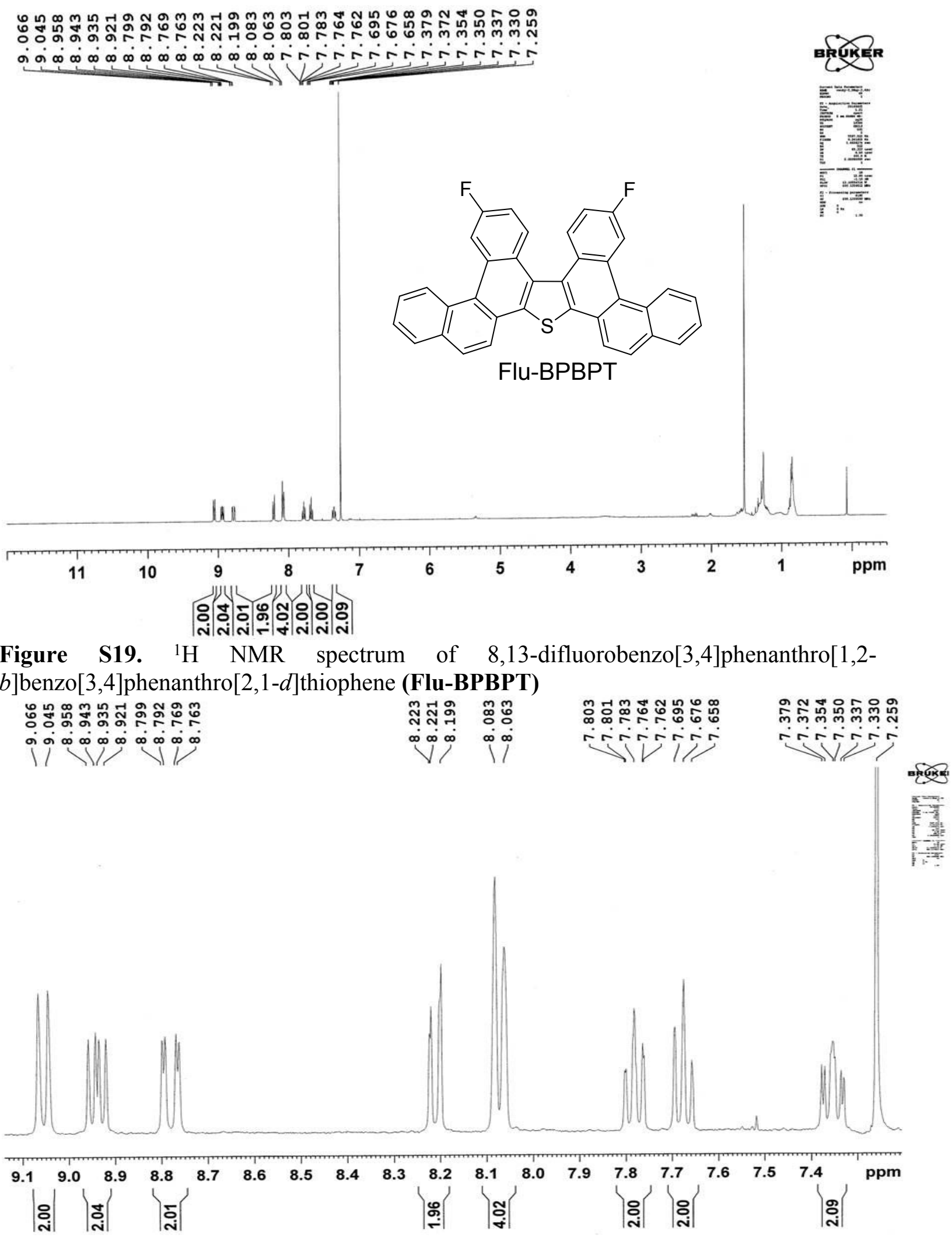

Figure S20. Expanded ${ }^{1} \mathrm{H}$ NMR spectrum of 8,13-difluorobenzo[3,4]phenanthro[1,2$b]$ benzo[3,4]phenanthro[2,1-d] thiophene (Flu-BPBPT) 


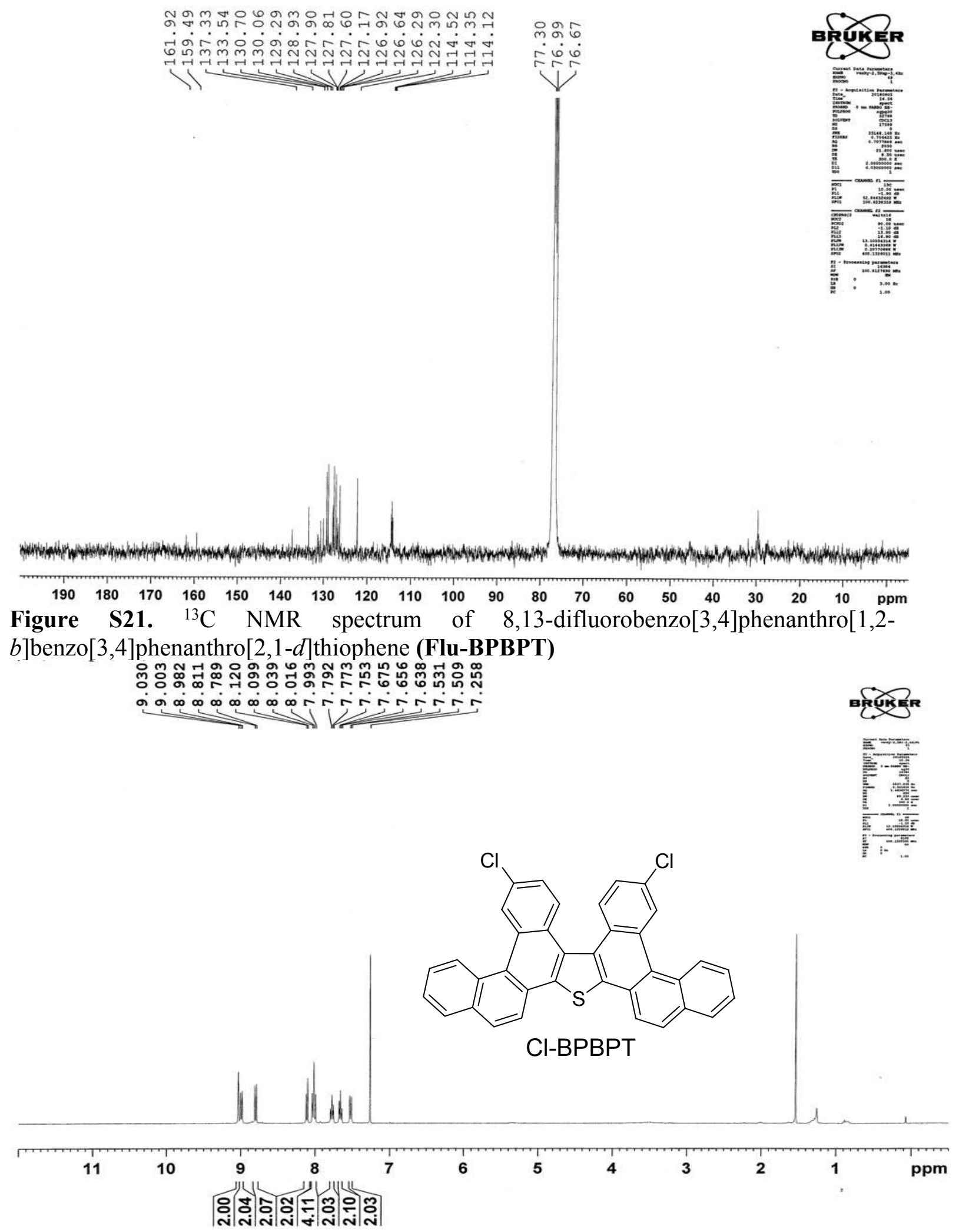

Figure $\quad$ S22. $\quad{ }^{1} \mathrm{H} \quad$ NMR spectrum of 8,13-dichlorobenzo[3,4]phenanthro[1,2b]benzo[3,4]phenanthro[2,1-d] thiophene (Cl-BPBPT) 


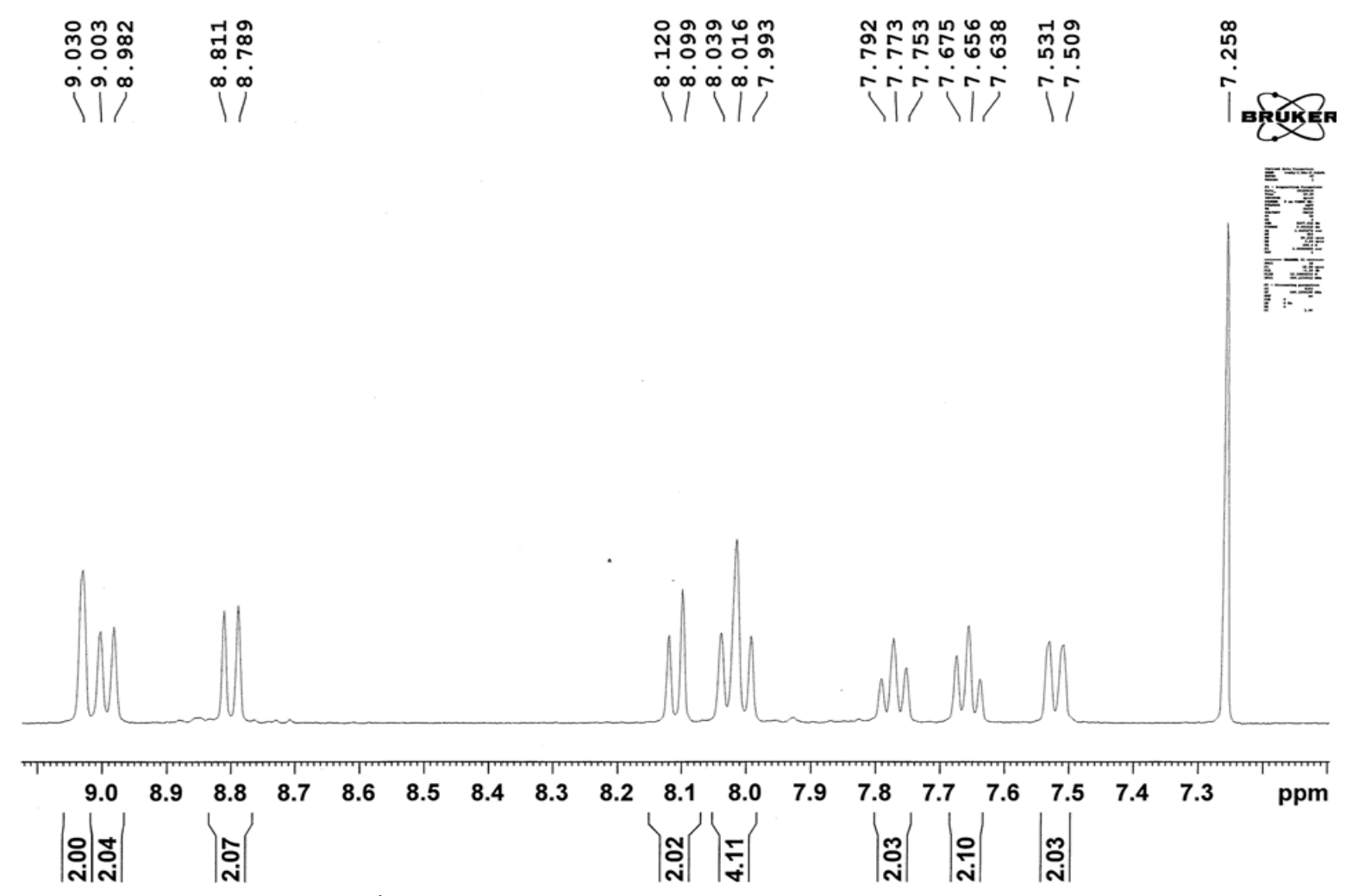

Figure S23. Expanded ${ }^{1} \mathrm{H}$ NMR spectrum of 8,13-dichlorobenzo[3,4]phenanthro[1,2$b]$ benzo[3,4]phenanthro[2,1-d] thiophene (CI-BPBPT)
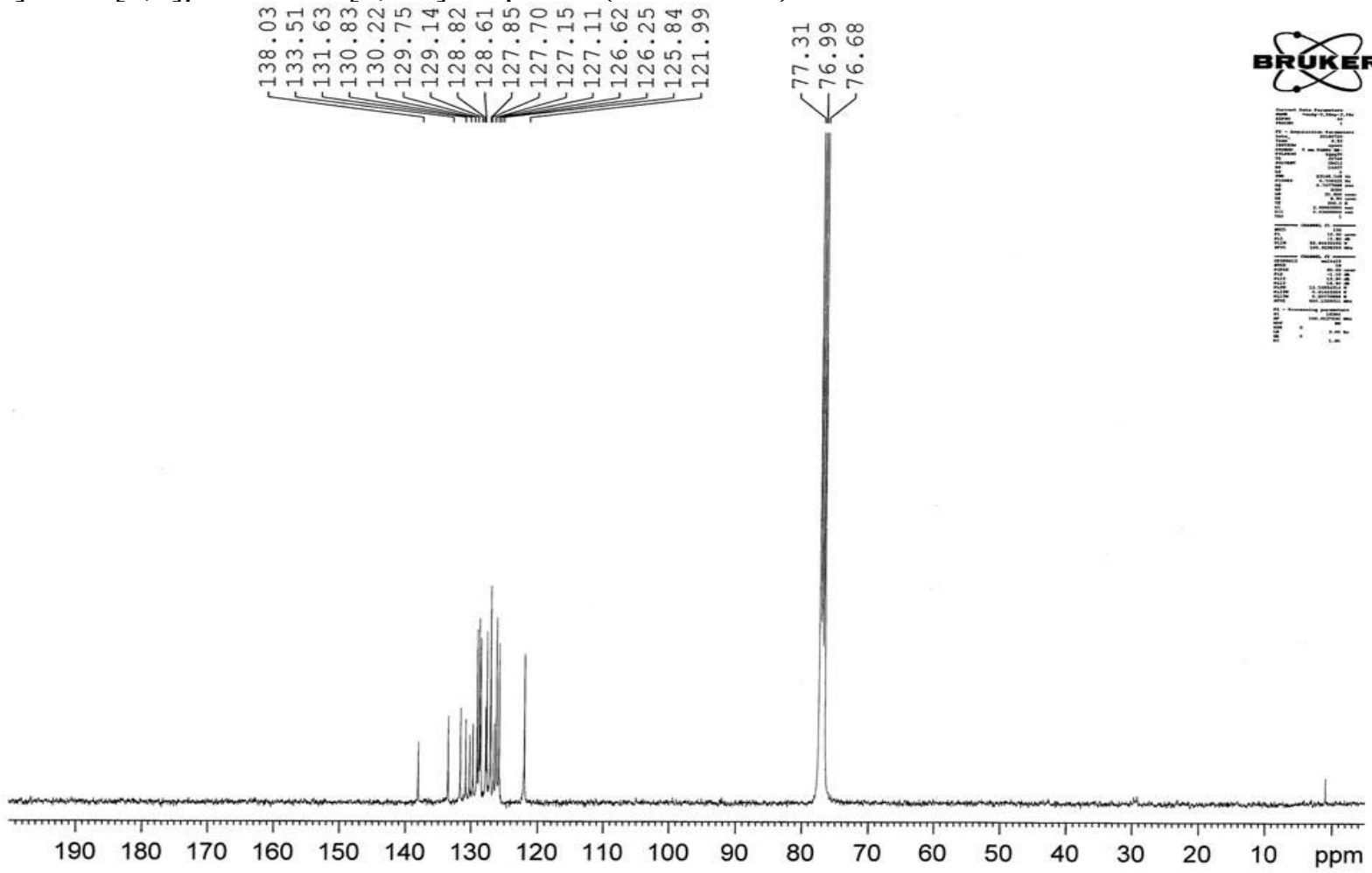

Figure S24. ${ }^{13} \mathrm{C}$ NMR spectrum of 8,13-dichlorobenzo[3,4]phenanthro[1,2$b]$ benzo[3,4]phenanthro[2,1-d] thiophene (Cl-BPBPT) 


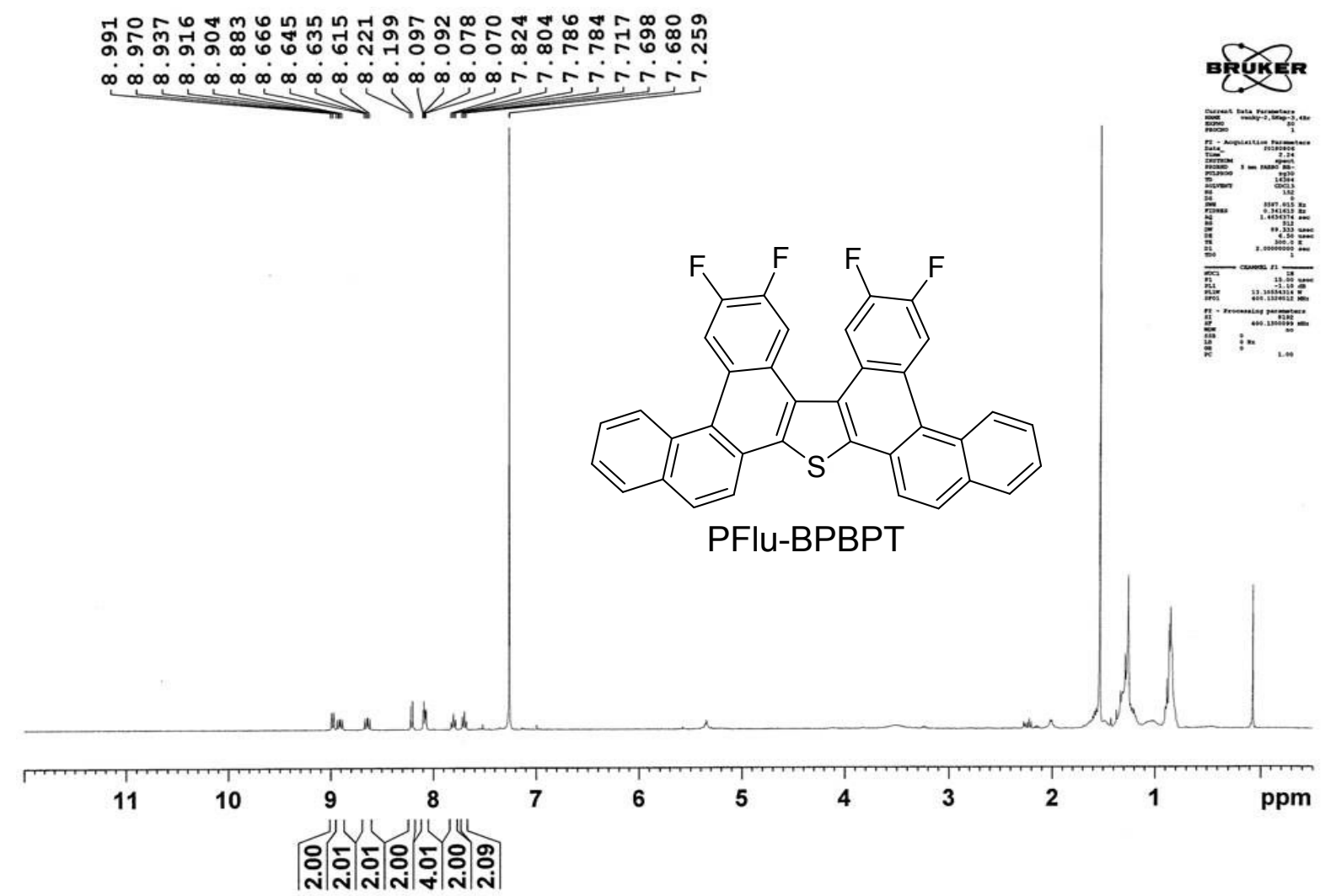

Figure S25. ${ }^{1} \mathrm{H}$ NMR spectrum of 8,9,12,13-tetrafluorobenzo[3,4]phenanthro[1,2$b]$ benzo[3,4]phenanthro[2,1-d] thiophene (PFlu-BPBPT)
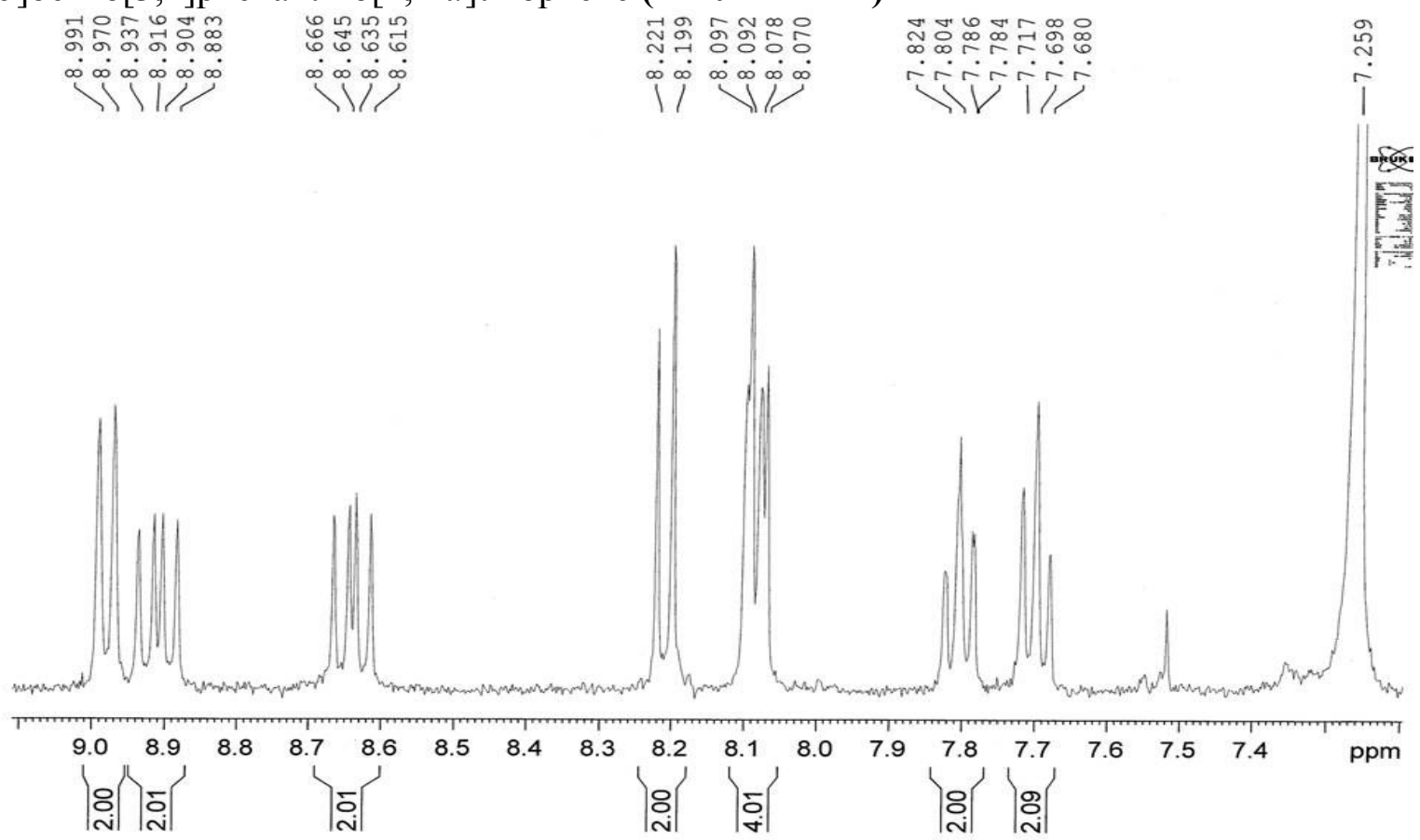

Figure S26. $\quad$ Expanded ${ }^{1} \mathrm{H} \quad \mathrm{NMR}$ spectrum of 8,9,12,13tetrafluorobenzo[3,4]phenanthro[1,2-b]benzo[3,4]phenanthro[2,1-d]thiophene $\quad$ (PFluBPBPT) 


\section{High-resolution MALDI-TOF mass spectra of BPBPTs.}

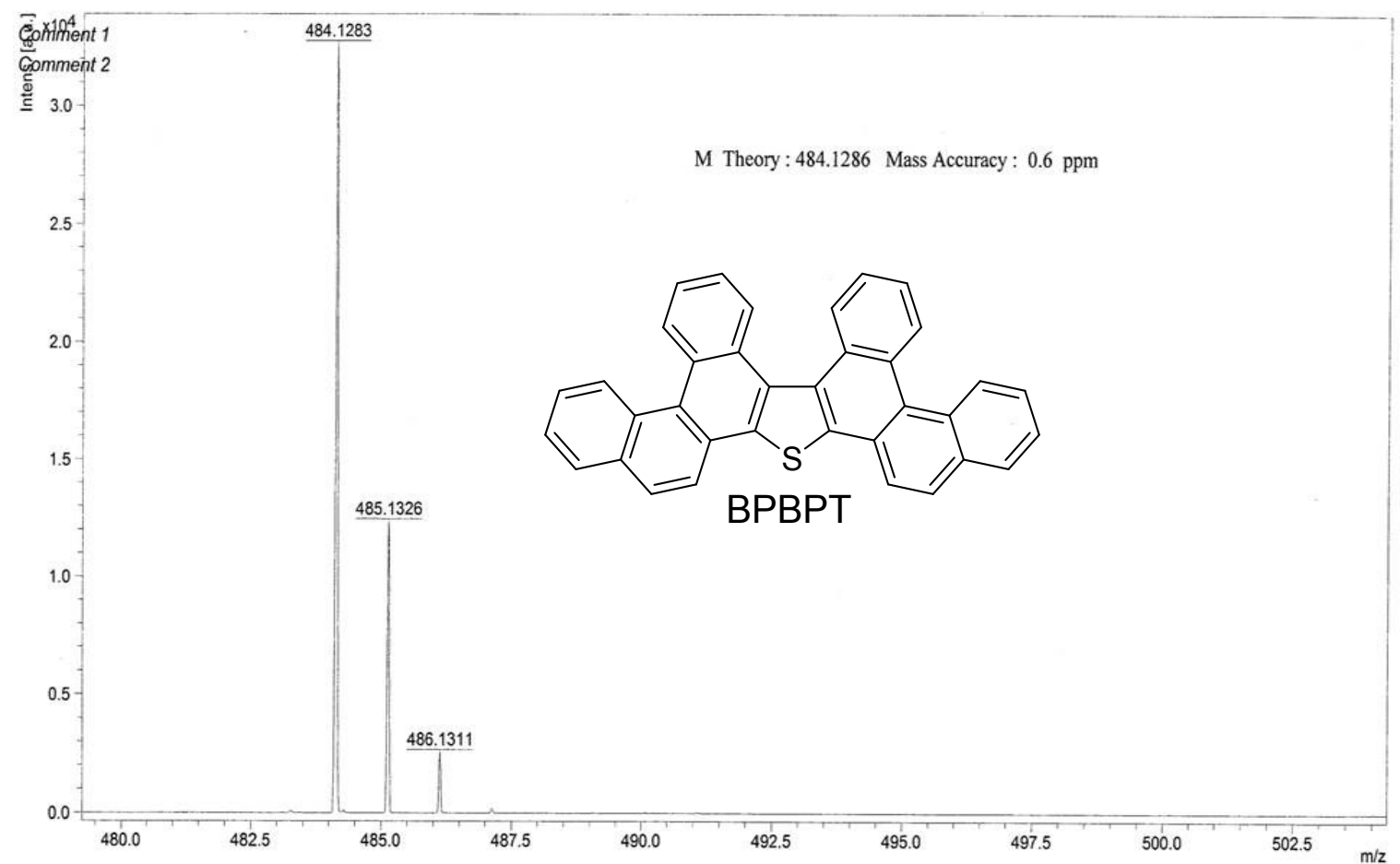

Figure S27. MALDI-TOF mass spectrum of benzo[3,4]phenanthro[1,2-b] benzo[3,4]phenanthro[2,1- $d]$ thiophene (BPBPT).

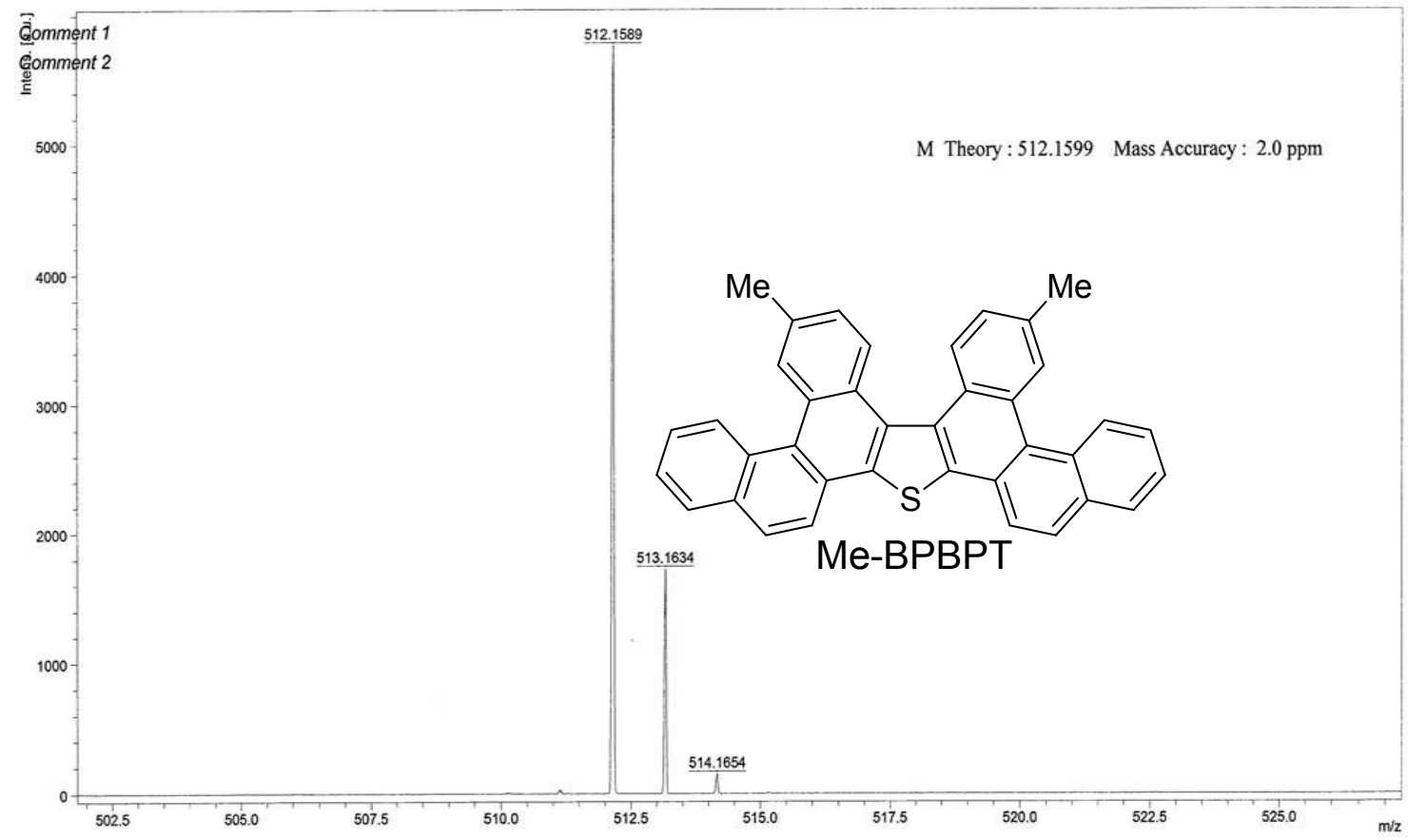

Figure S28. MALDI-TOF mass spectrum of

8,13-dimethylbenzo[3,4]phenanthro[1,2-b]benzo[3,4]phenanthro[2,1- $d]$ thiophene (Me-BPBPT). 


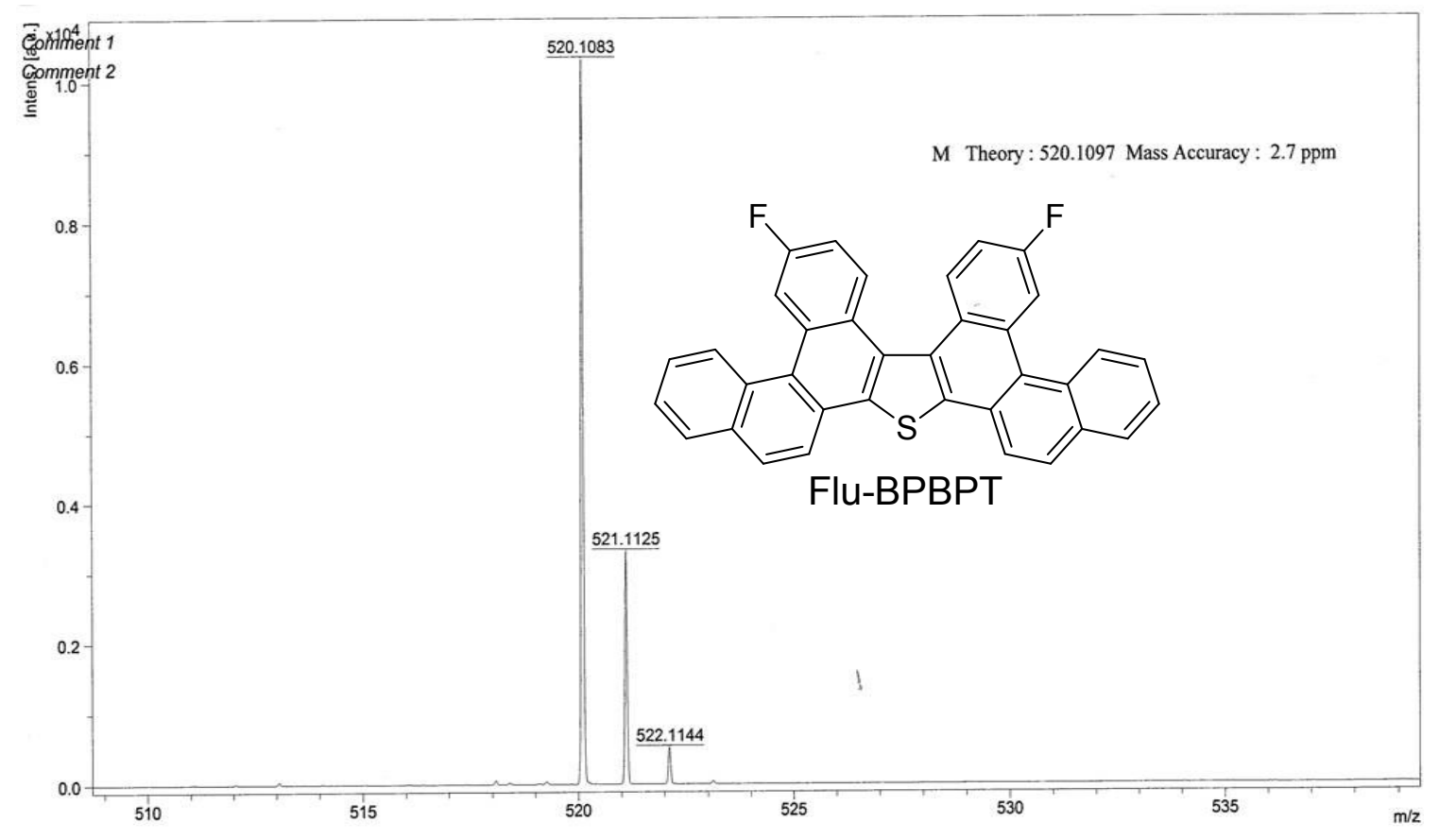

Figure S29. MALDI-TOF mass spectrum of

8,13-difluorobenzo[3,4]phenanthro[1,2-b] benzo[3,4]phenanthro[2,1- $d]$ thiophene (Flu-BPBPT).

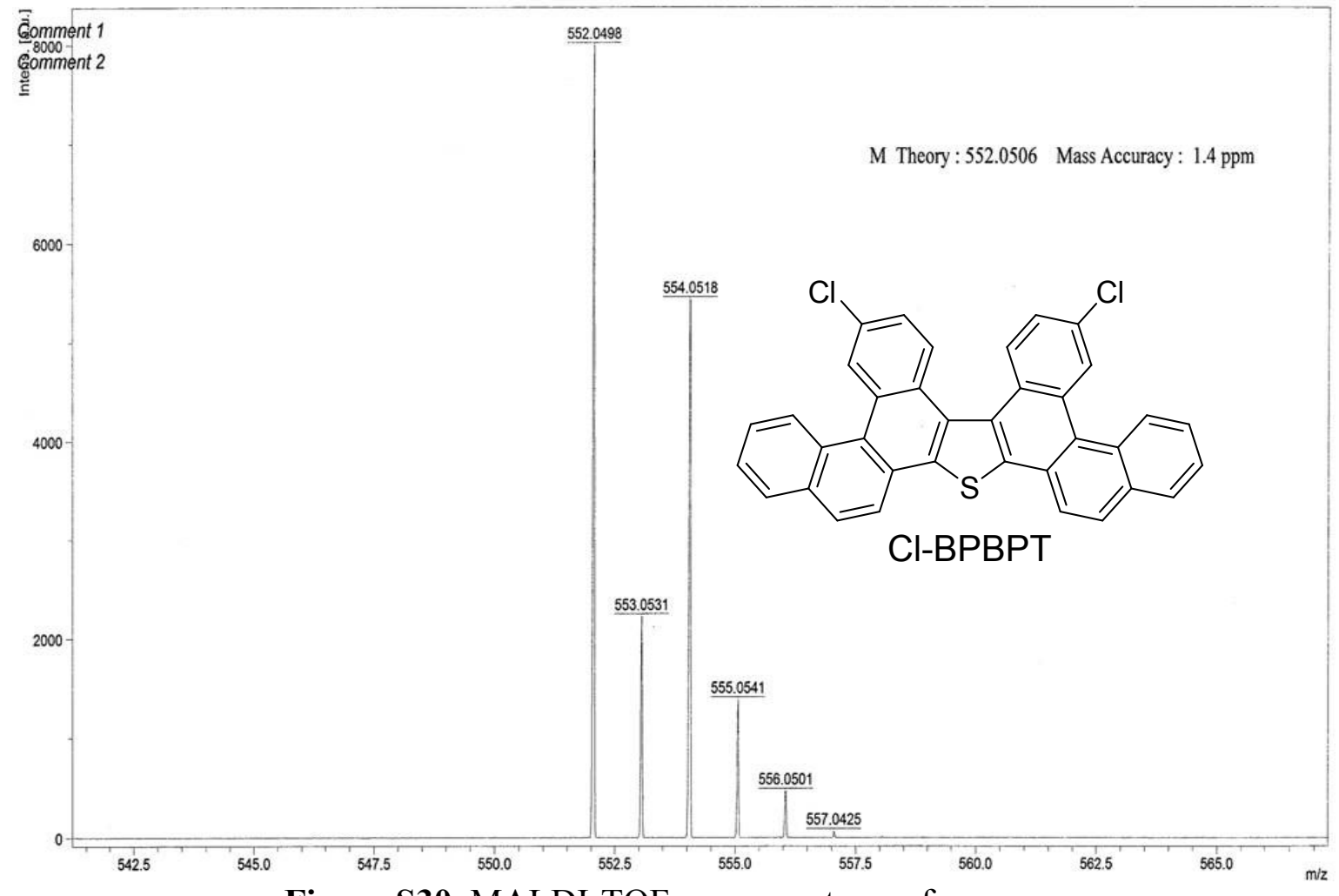

Figure S30. MALDI-TOF mass spectrum of

8,13-dichlorobenzo[3,4]phenanthro[1,2-b]benzo[3,4]phenanthro[2,1-d] thiophene

(Cl-BPBPT). 


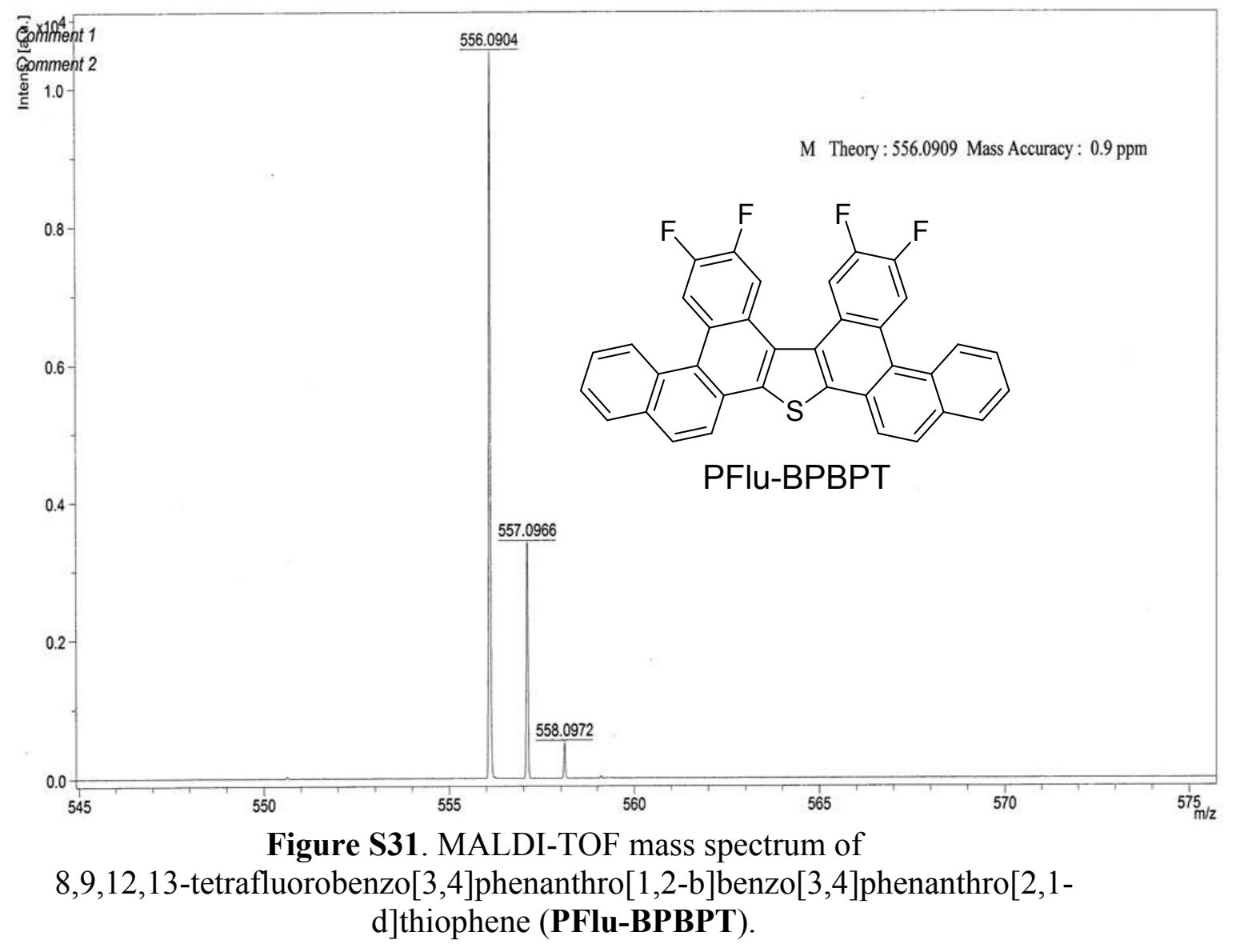


4. Thermal ellipsoid plots of BPBPT, Me-BPBPT, Flu-BPBPT, Cl-BPBPT and PFlu-BPBPT

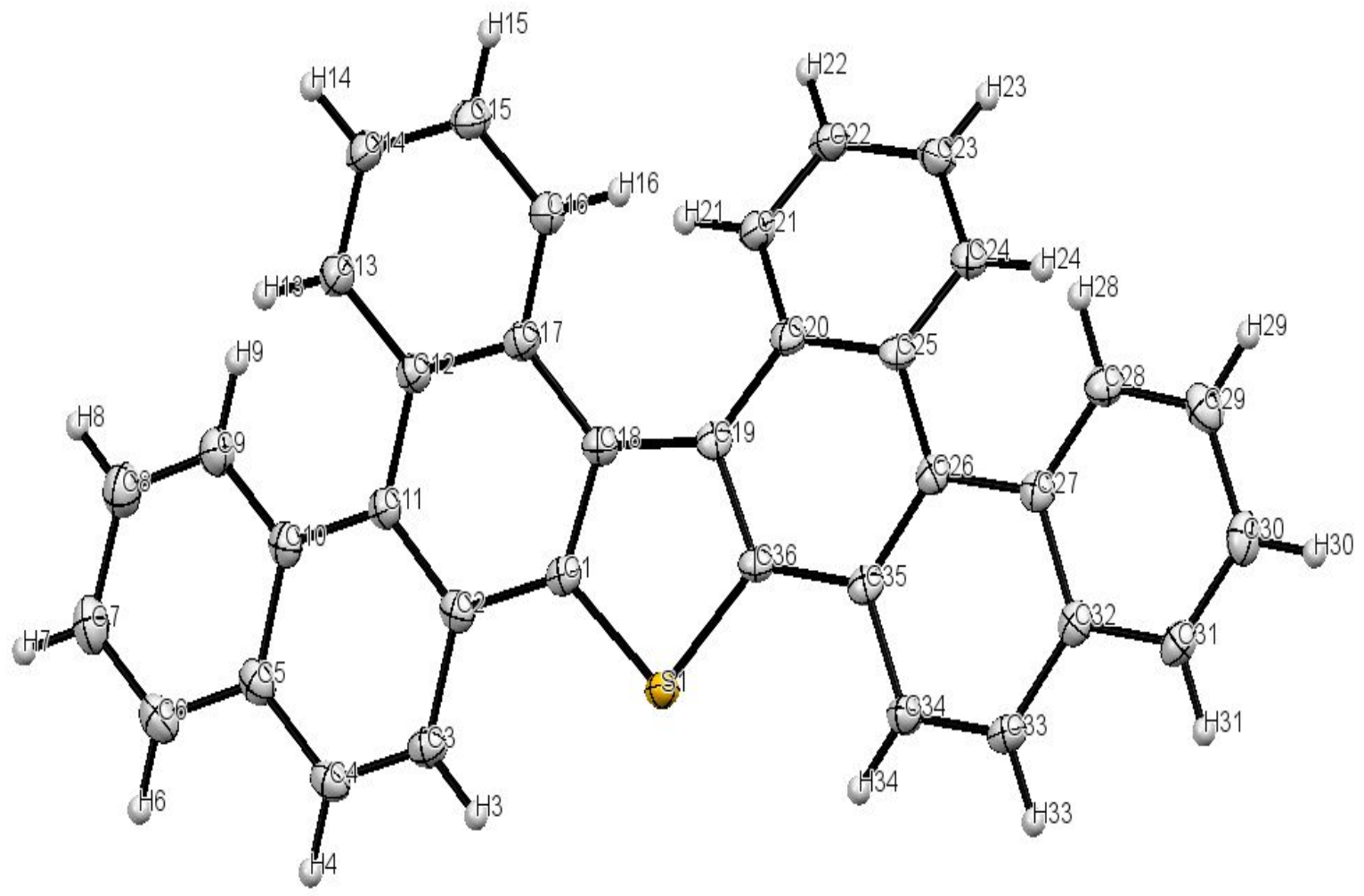

(a) BPBPT (50\%) 


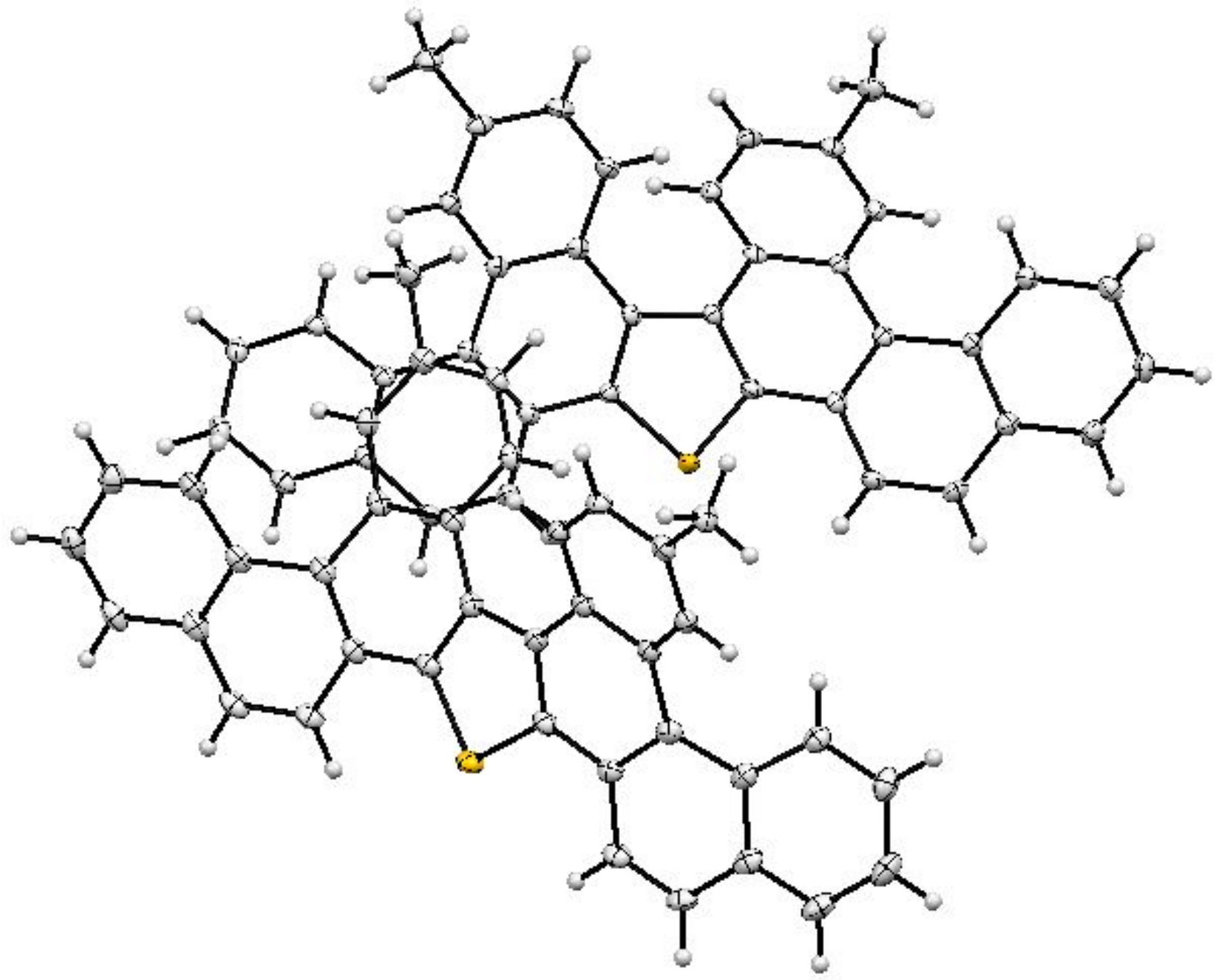

(b) Me-BPBPT (50\%) 


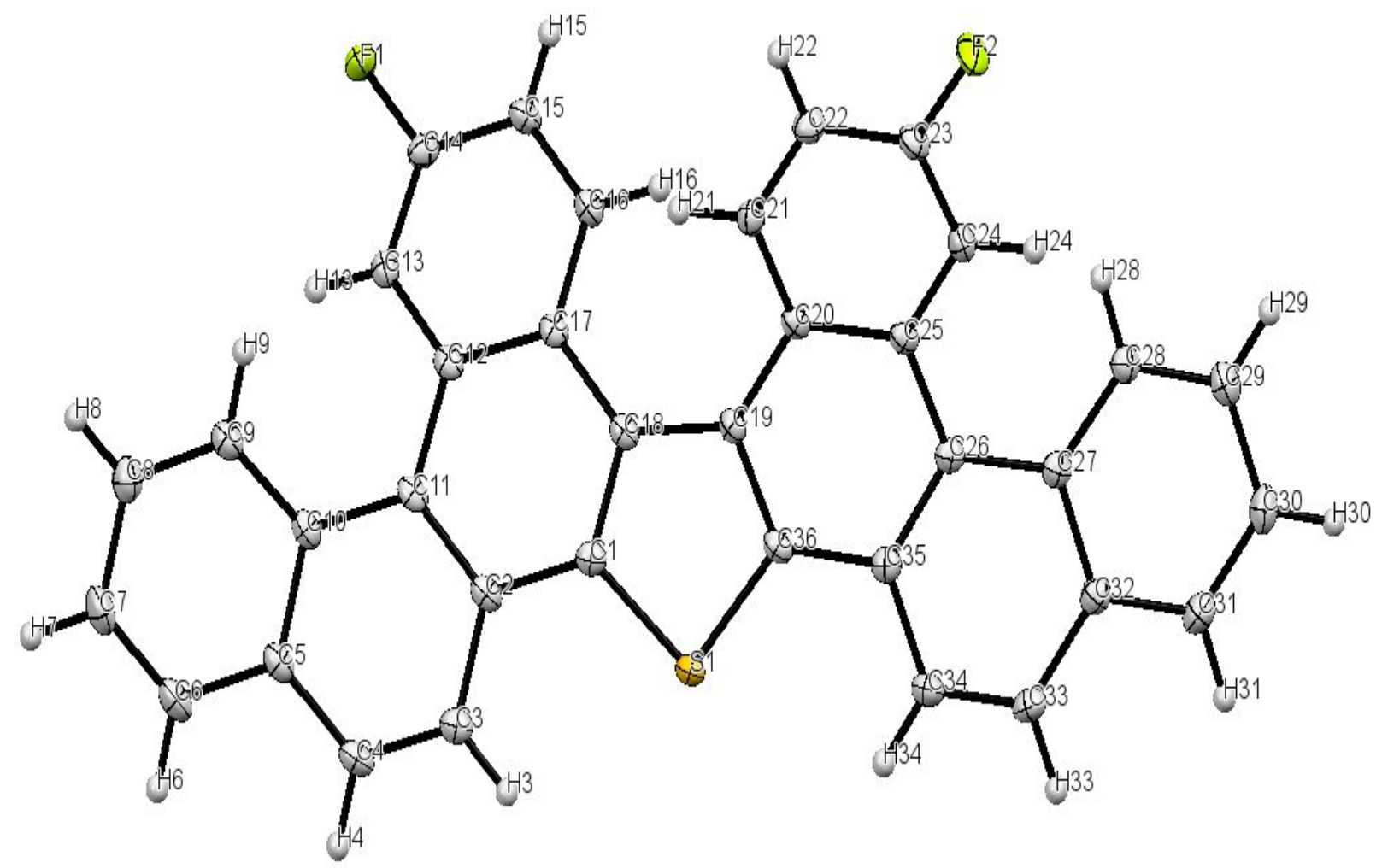

(c) Flu-BPBPT (50\%) 


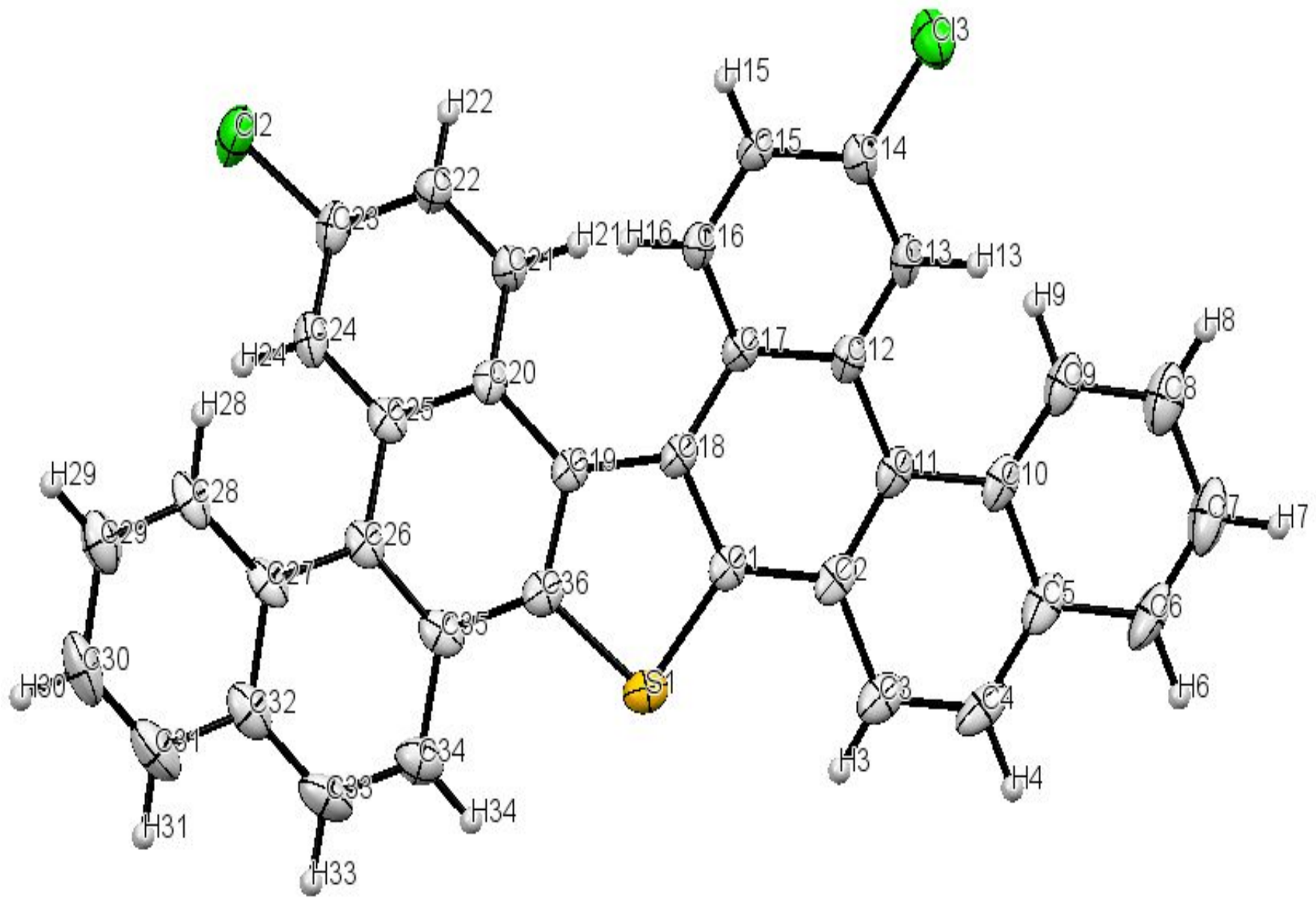

(d) Cl-BPBPT (50\%) 


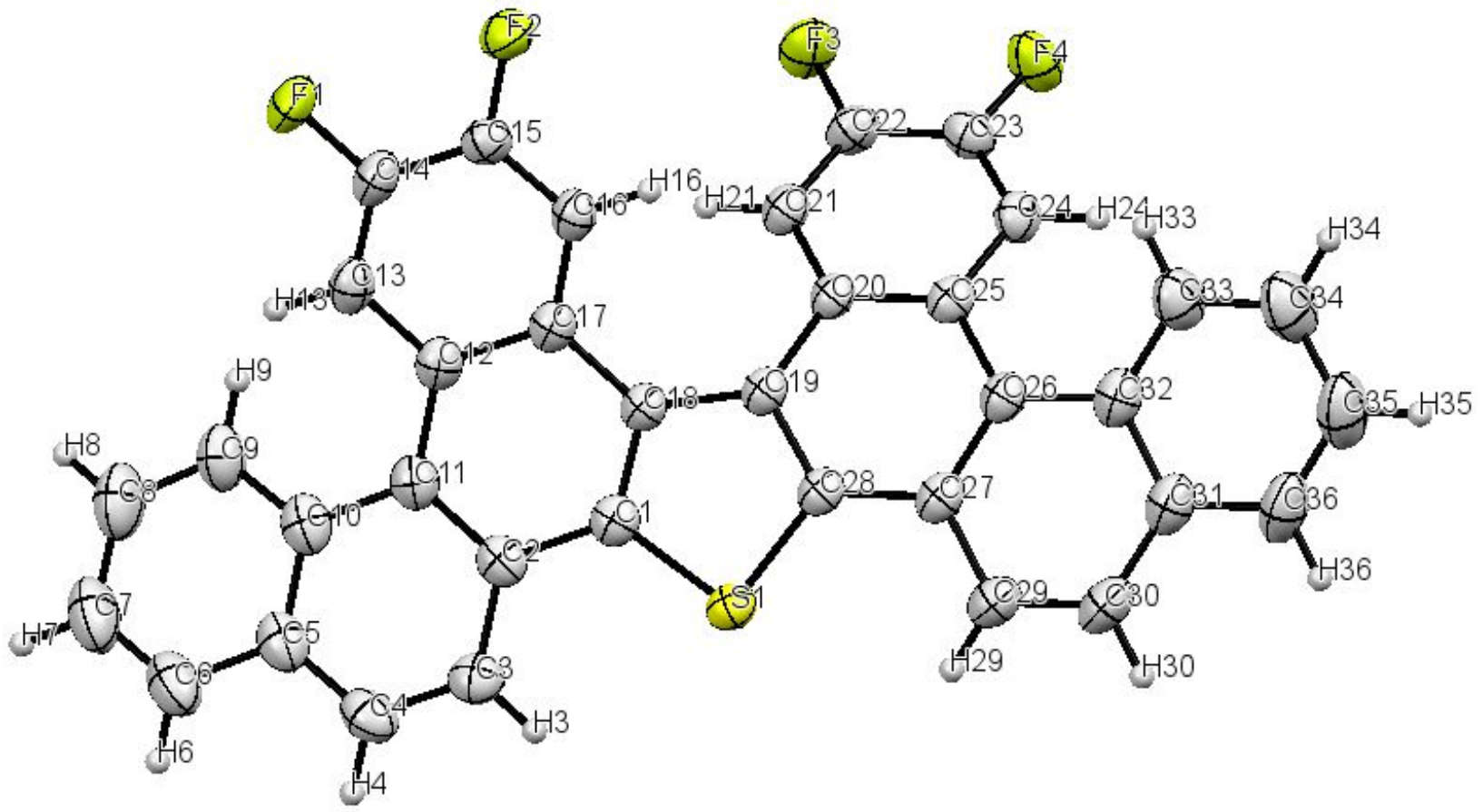

(e) PFlu-BPBPT (50\%)

Figure S32. Thermal ellipsoids of BPBPTs (probability levels). 
Table S1. Dipole moments of BPBPTs (Calculated by Spartan pro by semi empirical method at AM1 level).

\begin{tabular}{|l|l|}
\hline Compound & $\begin{array}{l}\text { Dipole } \\
\text { (Debye) }\end{array}$ \\
\hline BPBPT & 0.34 \\
\hline Me-BPBPT & 1.14 \\
\hline Flu-BPBPT & 1.83 \\
\hline Cl-BPBPT & 2.98 \\
\hline PFlu-BPBPT & 4.13 \\
\hline
\end{tabular}


5. Normalized absorption and emission spectra of BPBPTs.

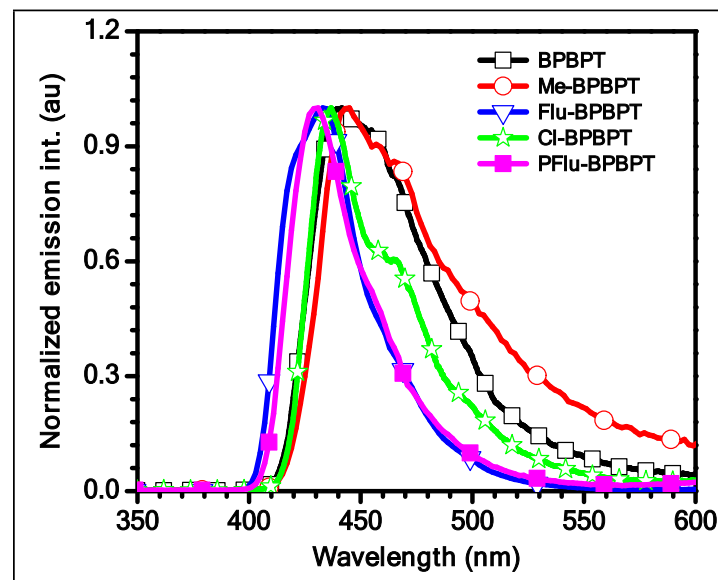

(a)

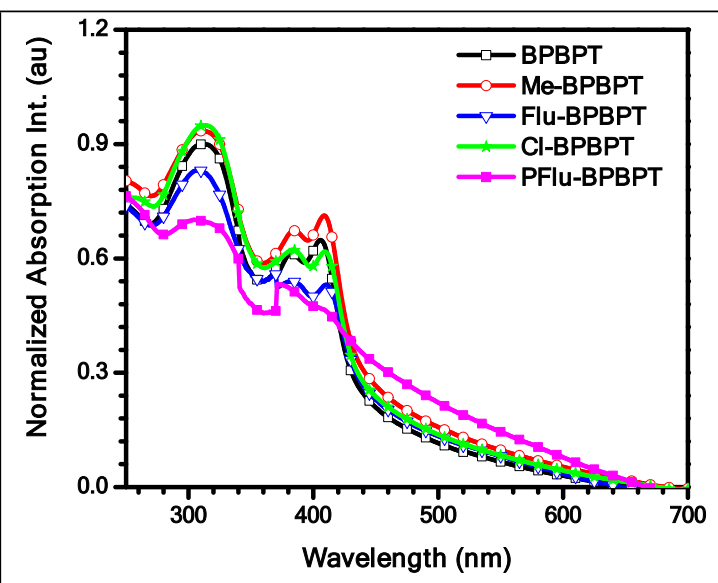

(b)

Figure S33. (a) Normalized emission spectra of BPBPTs in dichloromethane. (b)

Normalized absorption spectra of BPBPTs as recorded in solid state.

\section{HOMO-LUMO plots of BPBPTs.}

\section{Compd. BPBPT}

Me-BPBPT

Flu-BPBPT
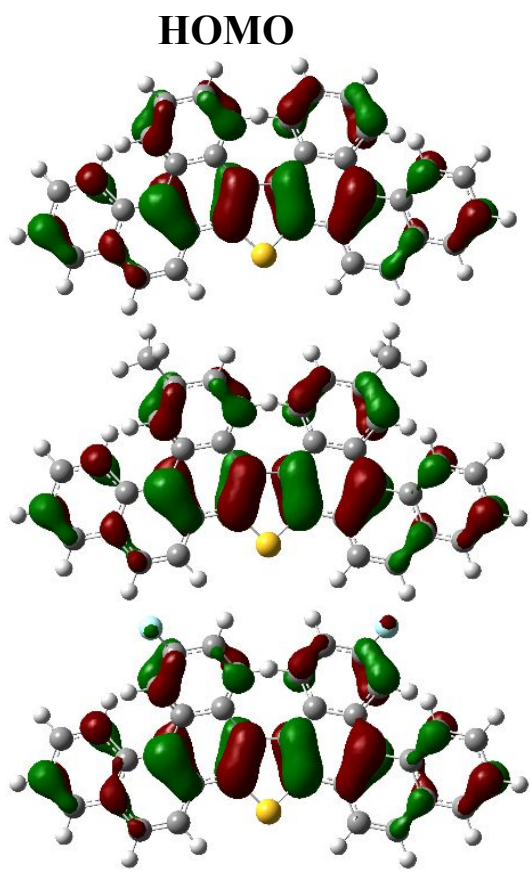

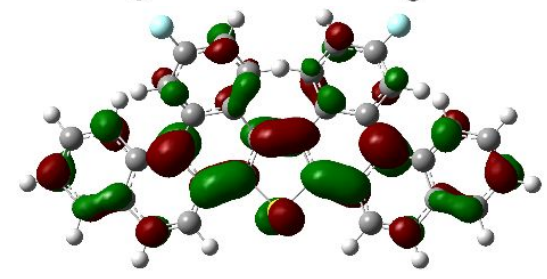




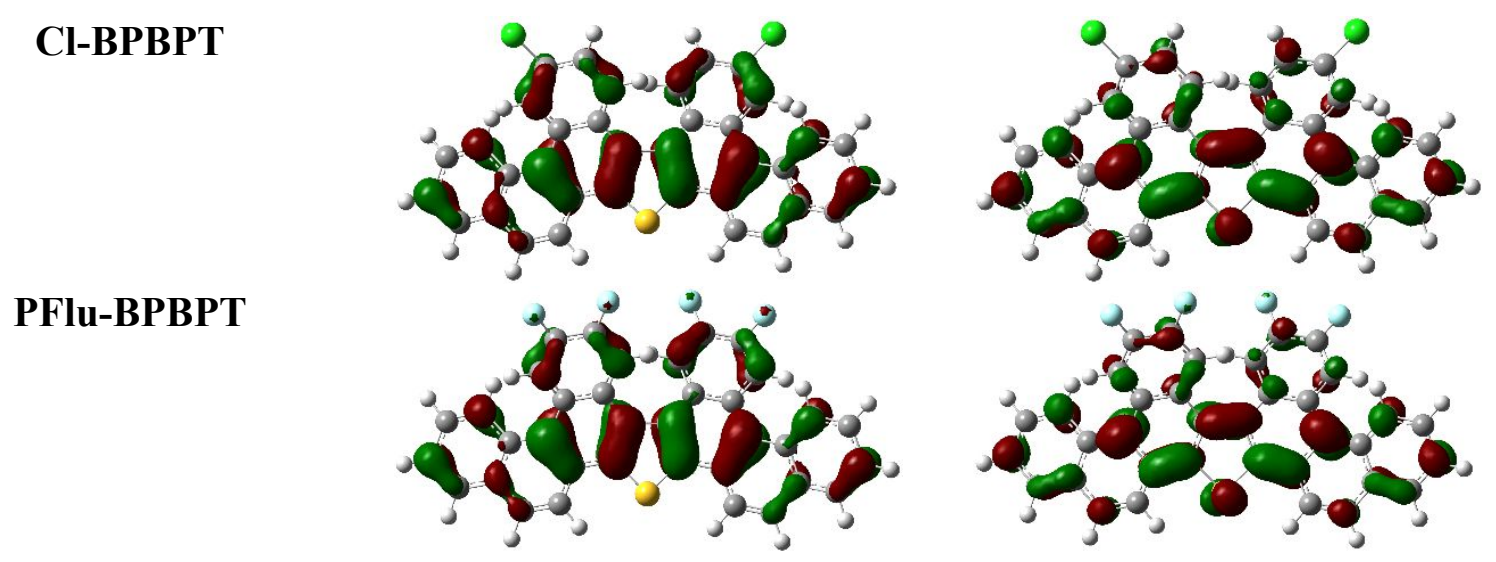

Figure S34. Frontier molecular orbitals of BPBPTs.

7. Thermogravimetric plots of BPBPTs

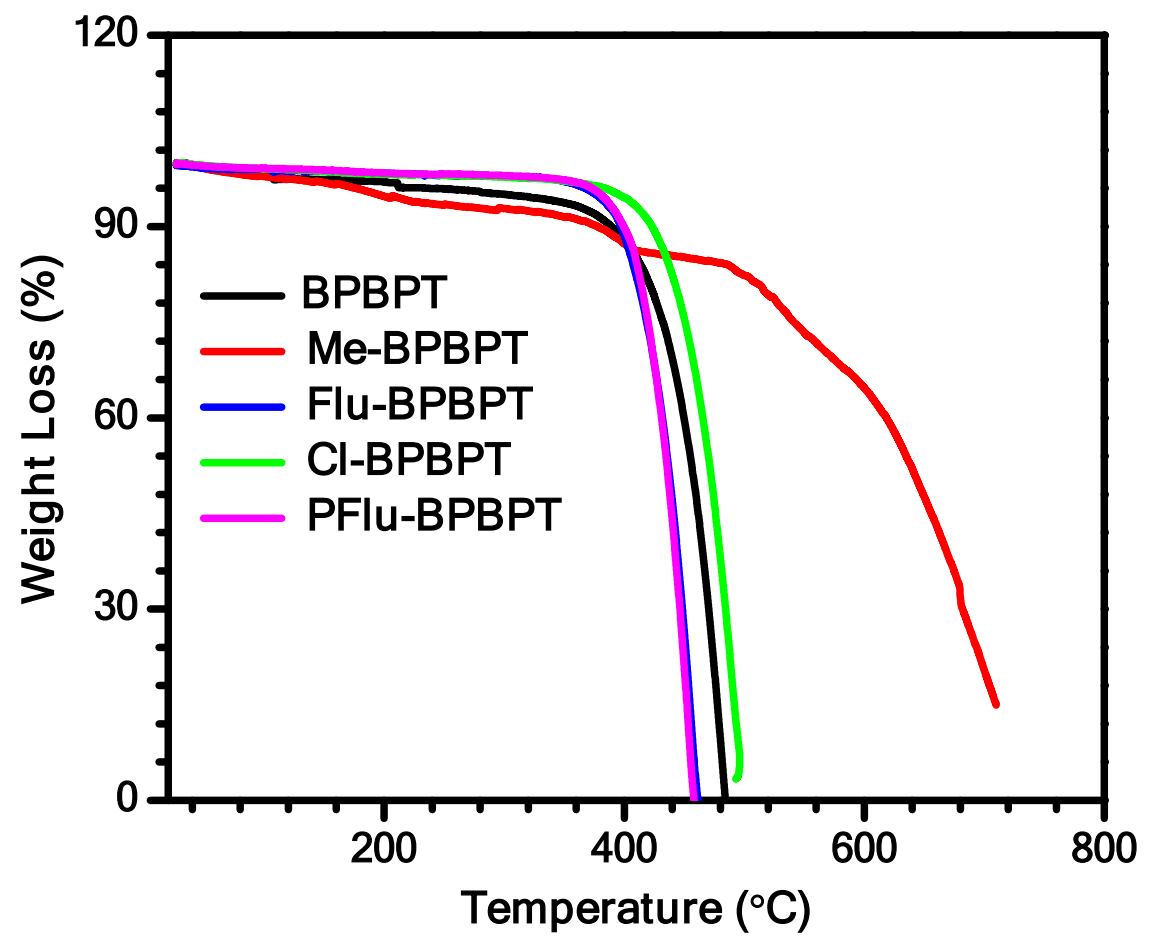

Figure S35. Thermogravimetric plots of BPBPT 
8. The molecular packings and neighboring dimers (Dn).

(a)

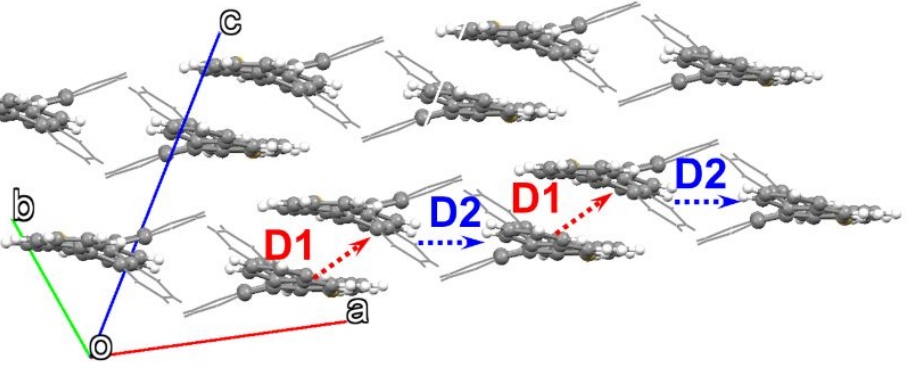

(c)

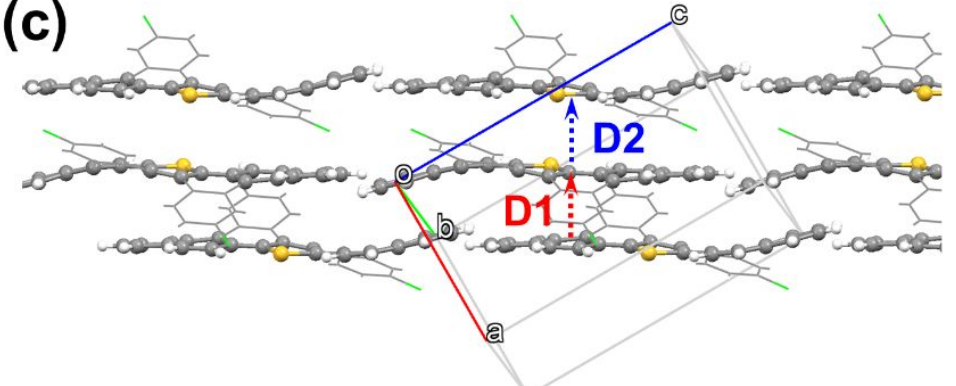

(e)

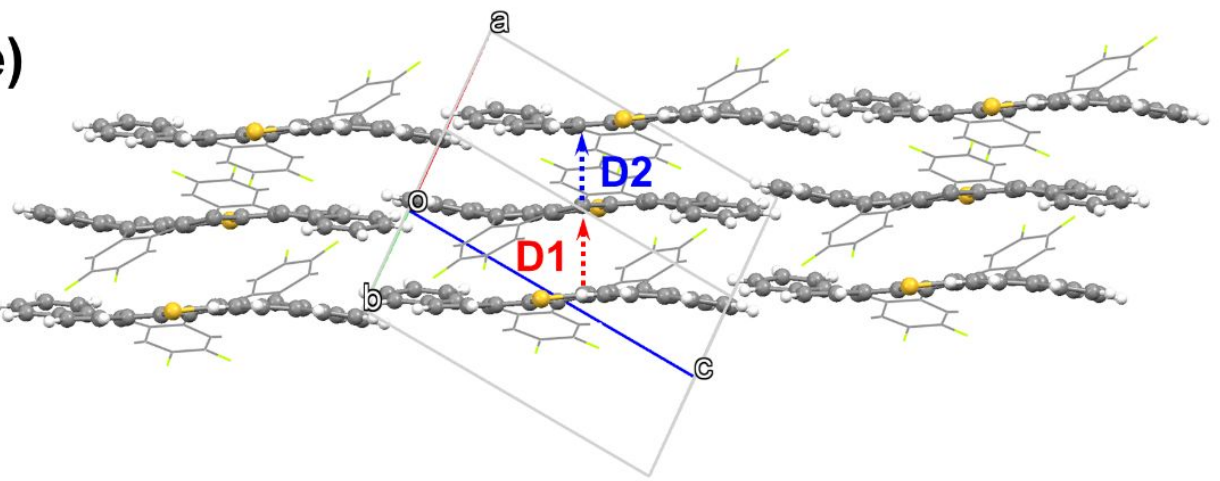

(b)

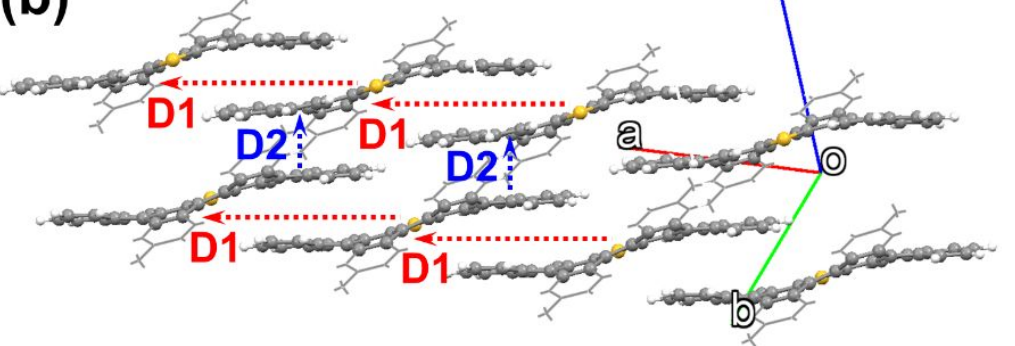

(d)

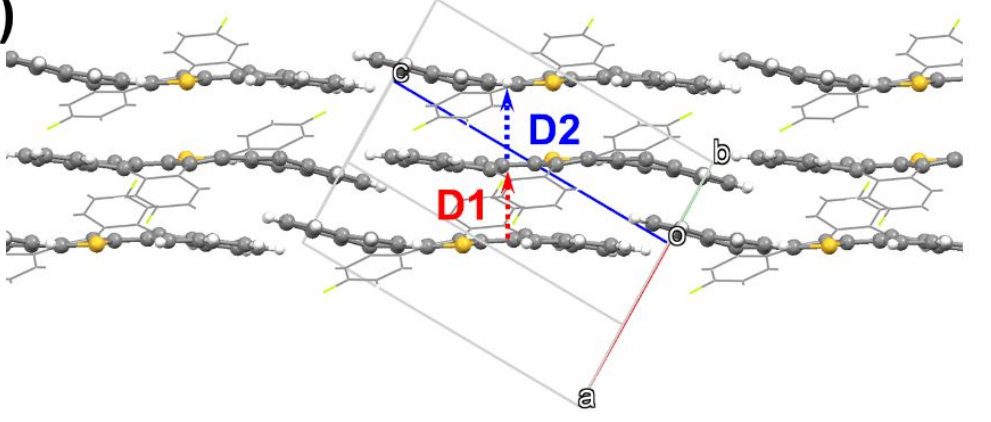

Figure S36. The molecular packings and neighboring dimers (Dn) of (a) BPBPT, (b) Me-BPBPT, (c) Cl-BPBPT, (d) FluBPBPT, and (e) PFlu-BPBPT. For clarification, the benzene rings with substituents are presented by wireframe molecular models, respectively. 
9. Single-crystals field-effect transistor of BPBPT and its transistor characteristics.

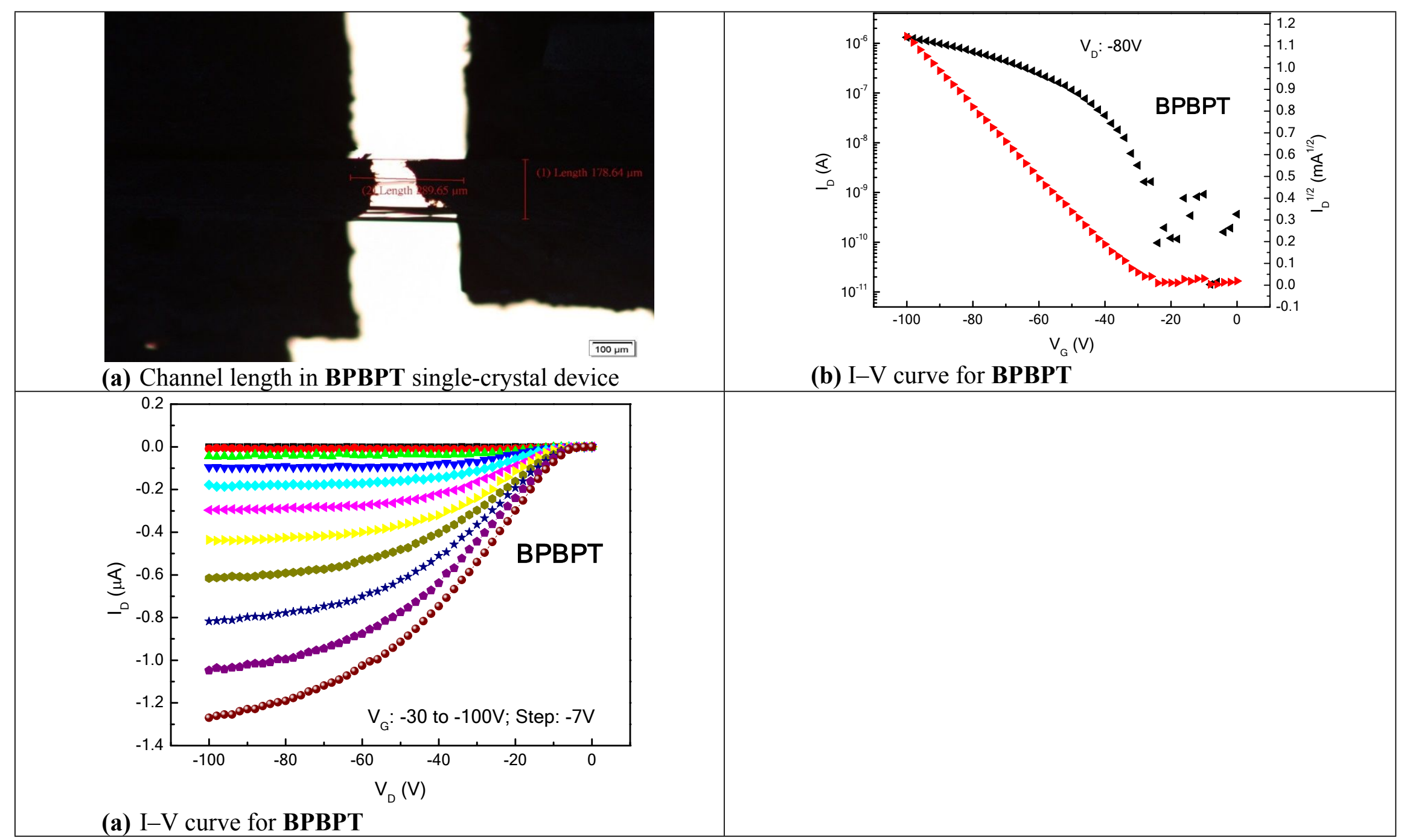




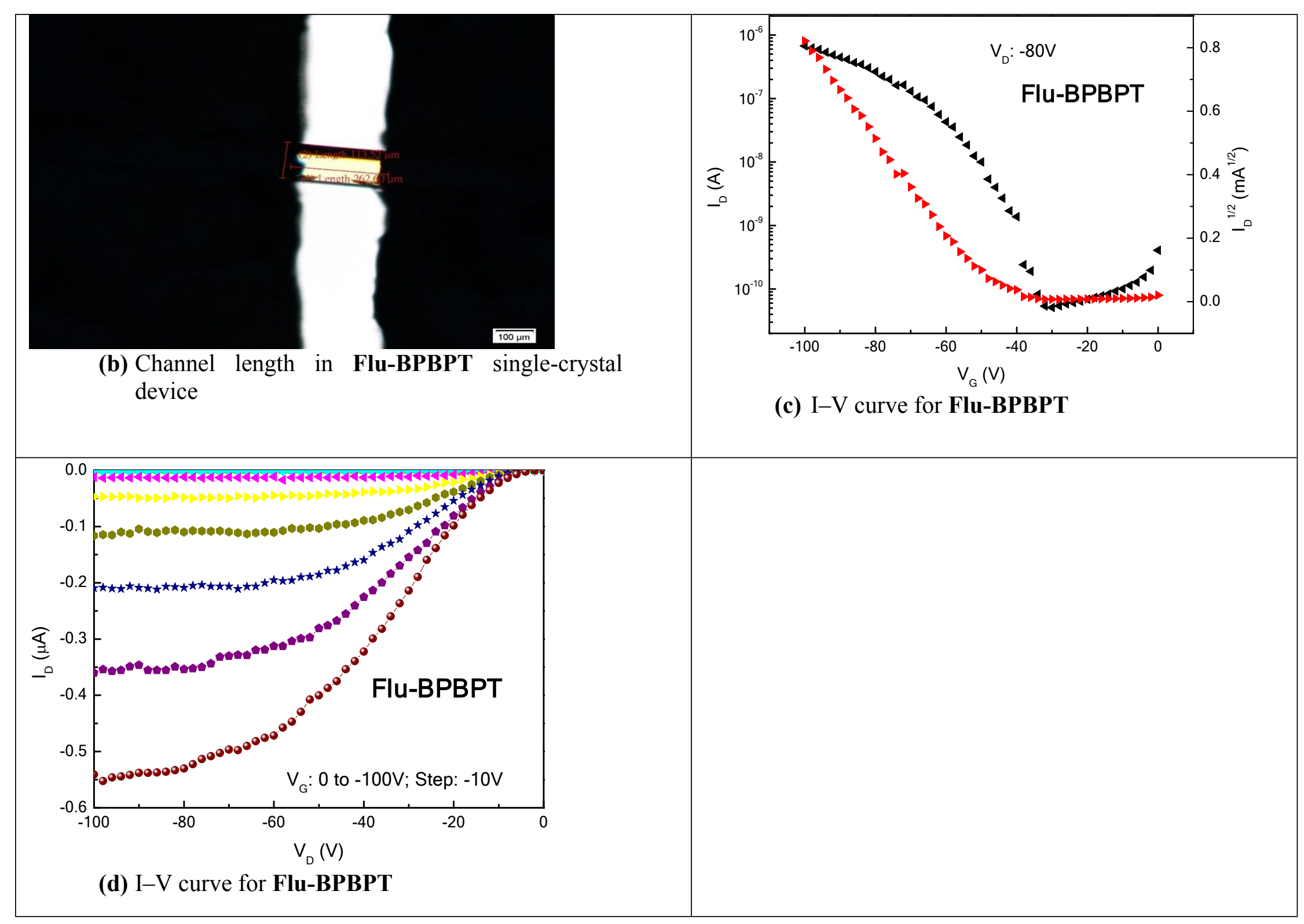




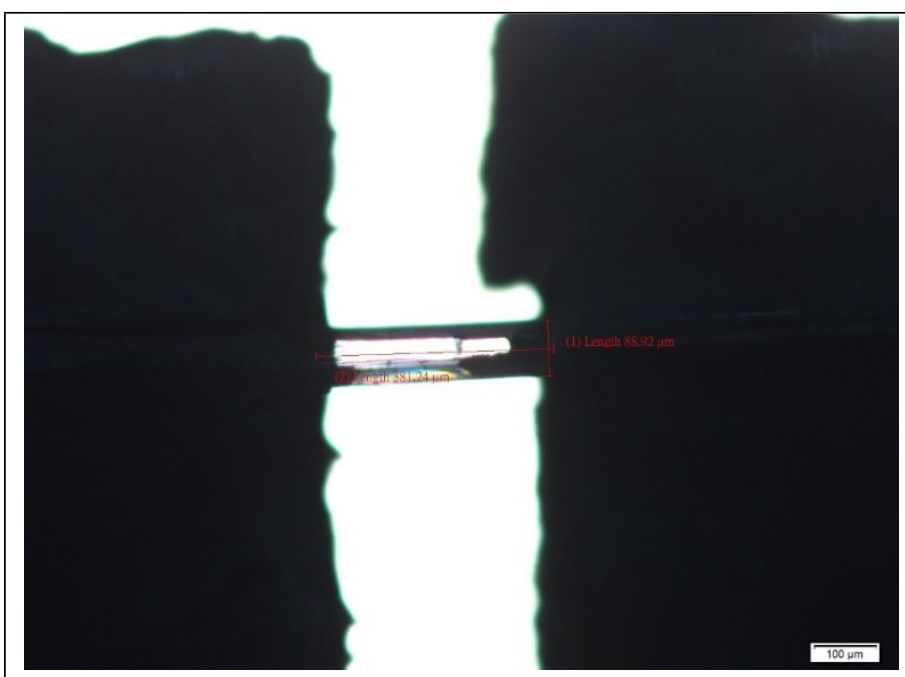

(e) Channel length in Cl-BPBPT single-crystal device

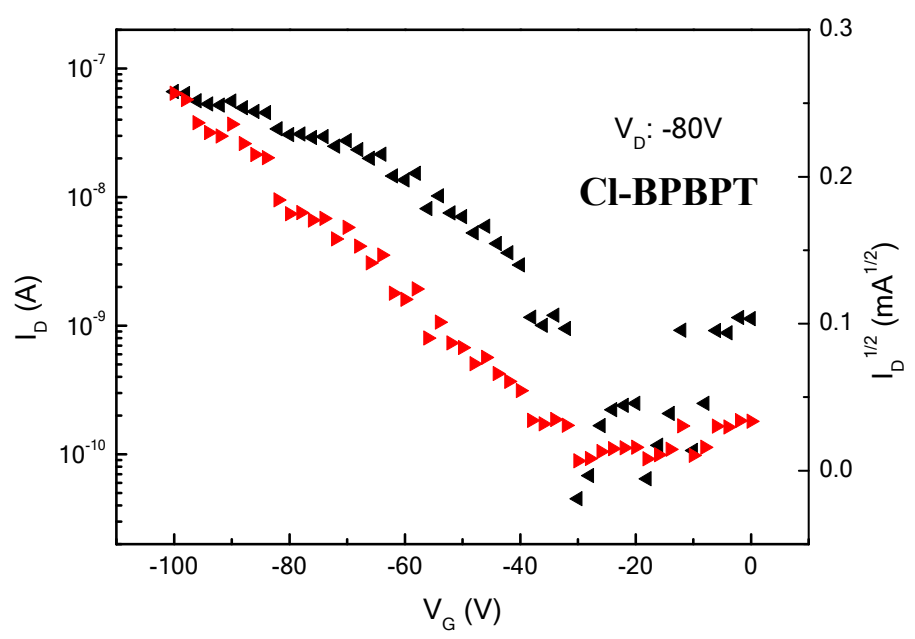

(f) $\mathrm{I}-\mathrm{V}$ curve for $\mathrm{Cl}-\mathrm{BPBPT}$

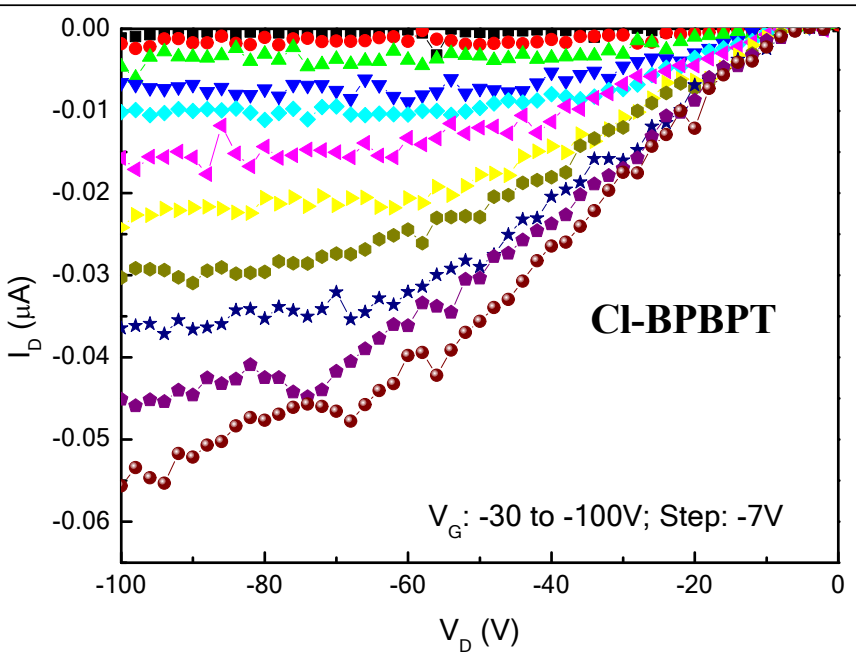

(g) I-V curve for Cl-BPBPT 


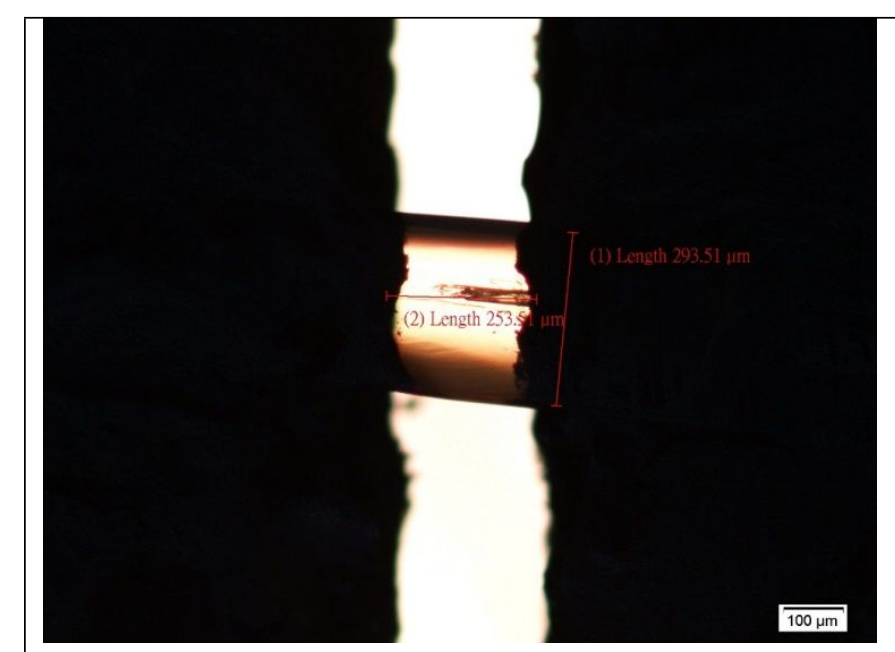

(h) Channel length in PFlu-BPBPT singlecrystal device

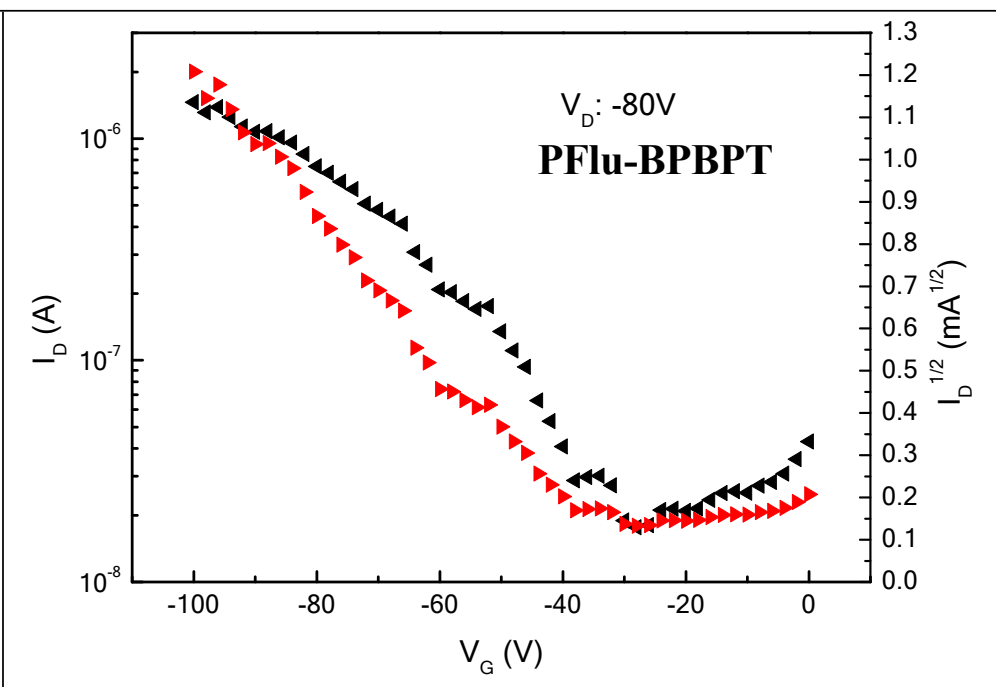

(k) I-V curve for PFlu-BPBPT

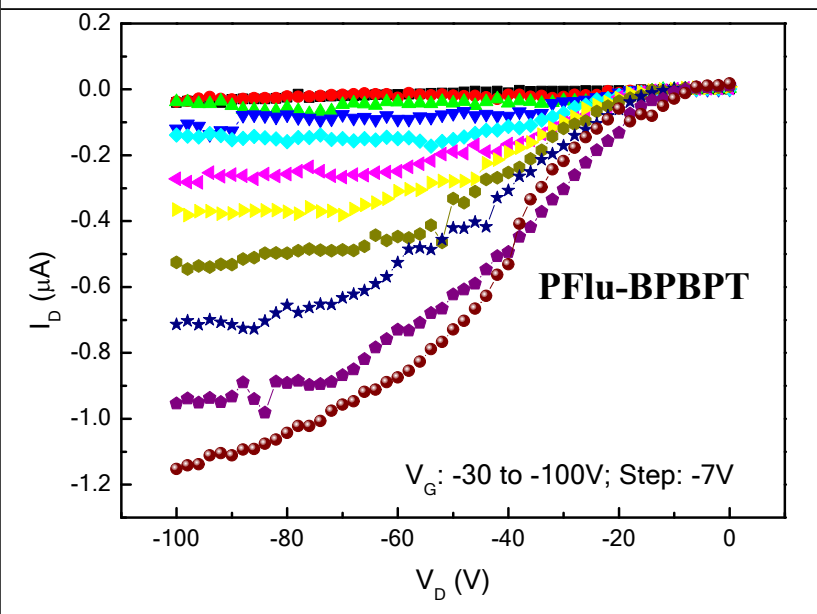

(I) I-V curve for PFlu-BPBPT 
Figure S37. Single-crystals of BPBPT,Flu-BPBPT,Cl-BPBPT and PFlu-BPBPT in SCFET device and their I-V curves. 
Table S2. SCFET data for BPBPT

\begin{tabular}{|l|l|l|}
\hline $\begin{array}{l}\boldsymbol{\mu}_{\mathbf{h}} \\
\left(\mathbf{c m}^{\mathbf{2}} \mathbf{V}^{-\mathbf{1}} \mathbf{s}^{\mathbf{1}}\right)\end{array}$ & $\mathbf{V}_{\text {th }}(\mathbf{V})$ & $\mathbf{I}_{\mathbf{o n}} \mathbf{I}_{\mathbf{o f f}}$ \\
\hline 0.338 & -48.4 & $2.00 \times 10^{2}$ \\
\hline 0.342 & -35.6 & $2.24 \times 10^{2}$ \\
\hline 0.629 & -33.8 & $1.08 \times 10^{3}$ \\
\hline 1.22 & -29.9 & $3.82 \times 10^{3}$ \\
\hline 1.02 & -36.7 & $1.43 \times 10^{3}$ \\
\hline 0.997 & -28.4 & $2.00 \times 10^{4}$ \\
\hline 1.03 & -32.5 & $1.05 \times 10^{4}$ \\
\hline 0.19 & -35.1 & $2.09 \times 10^{2}$ \\
\hline 0.637 & -36.6 & $4.93 \times 10^{2}$ \\
\hline 0.709 & -37.9 & $1.06 \times 10^{3}$ \\
\hline 0.372 & -33.7 & $6.34 \times 10^{2}$ \\
\hline
\end{tabular}

Table S3. SCFET data for Flu-BPBPT

\begin{tabular}{|l|l|l|}
\hline $\begin{array}{l}\boldsymbol{\mu}_{\mathbf{h}} \\
\left(\mathbf{c m}^{\mathbf{2}} \mathbf{V}^{-1} \mathbf{s}^{-1}\right)\end{array}$ & $\mathbf{V}_{\text {th }}(\mathbf{V})$ & $\mathbf{I}_{\mathbf{o n}} / \mathbf{I}_{\mathbf{o f f}}$ \\
\hline 0.281 & -39.1 & $4.60 \times 10^{3}$ \\
\hline 0.251 & -50.0 & $8.11 \times 10^{3}$ \\
\hline 0.346 & -43.1 & $5.51 \times 10^{3}$ \\
\hline 0.384 & -55.3 & $8.10 \times 10^{3}$ \\
\hline 0.695 & -37.8 & $2.45 \times 10^{4}$ \\
\hline 0.851 & -31.7 & $8.36 \times 10^{3}$ \\
\hline 0.368 & -38.9 & $6.08 \times 10^{3}$ \\
\hline 0.953 & -34.9 & $1.00 \times 10^{4}$ \\
\hline 1.17 & -34.0 & $9.56 \times 10^{3}$ \\
\hline 1.33 & -40.1 & $1.48 \times 10^{4}$ \\
\hline 2.03 & -47.8 & $1.31 \times 10^{4}$ \\
\hline 1.69 & -43.1 & $5.58 \times 10^{3}$ \\
\hline 0.872 & -42.7 & $5.93 \times 10^{3}$ \\
\hline 1.06 & -42.1 & $8.99 \times 10^{3}$ \\
\hline 0.886 & -43.8 & $6.00 \times 10^{3}$ \\
\hline 1.16 & -36.5 & $7.91 \times 10^{3}$ \\
\hline 0.859 & -47.1 & $2.11 \times 10^{3}$ \\
\hline
\end{tabular}

Table S4. SCFET data for CI-BPBPT

\begin{tabular}{|l|l|l|}
\hline $\begin{array}{l}\boldsymbol{\mu}_{\mathbf{h}} \\
\left(\mathbf{c m}^{2} \mathbf{V}^{-1} \mathbf{s}^{-1}\right)\end{array}$ & $\mathbf{V}_{\text {th }}(\mathbf{V})$ & $\mathbf{I}_{\text {on }} / \mathbf{I}_{\text {off }}$ \\
\hline $3.75 \times 10^{-2}$ & -27.2 & $3.47 \times 10^{1}$ \\
\hline
\end{tabular}




\begin{tabular}{|l|l|l|}
\hline $2.07 \times 10^{-2}$ & -33.5 & $4.02 \times 10^{1}$ \\
\hline $2.90 \times 10^{-2}$ & -38.4 & $2.58 \times 10^{1}$ \\
\hline $4.00 \times 10^{-2}$ & -29.7 & $6.82 \times 10^{1}$ \\
\hline $3.38 \times 10^{-2}$ & -30.5 & $4.35 \times 10^{1}$ \\
\hline $4.37 \times 10^{-2}$ & -28.8 & $1.90 \times 10^{1}$ \\
\hline $4.63 \times 10^{-2}$ & -24.5 & $4.15 \times 10^{1}$ \\
\hline $4.95 \times 10^{-2}$ & -24.6 & $5.79 \times 10^{1}$ \\
\hline $6.51 \times 10^{-2}$ & -25.7 & $2.75 \times 10^{1}$ \\
\hline
\end{tabular}

Table S5. SCFET data for PFlu-BPBPT

\begin{tabular}{|l|l|l|}
\hline $\begin{array}{l}\boldsymbol{\mu}_{\mathbf{h}} \\
\left(\mathbf{c m}^{\mathbf{2}} \mathbf{V}^{-1} \mathbf{s}^{-1}\right)\end{array}$ & $\mathbf{V}_{\text {th }}(\mathbf{V})$ & $\mathbf{I}_{\mathbf{o n}} / \mathbf{I}_{\mathbf{o f f}}$ \\
\hline 0.122 & -44.2 & $2.00 \times 10^{2}$ \\
\hline 0.145 & -42.7 & $6.79 \times 10^{2}$ \\
\hline 0.170 & -33.8 & $2.61 \times 10^{2}$ \\
\hline 0.206 & -33.4 & $7.14 \times 10^{2}$ \\
\hline 0.257 & -24.8 & $1.45 \times 10^{3}$ \\
\hline 0.437 & -36.1 & $5.77 \times 10^{1}$ \\
\hline 0.339 & -30.9 & $6.33 \times 10^{3}$ \\
\hline
\end{tabular}

\section{Single-crystal $X-$ ray data for BPBPT and Flu-BPBPT, Cl-BPBPT and PFlu-BPBPT BPBPT (CCDC)}

\begin{tabular}{|l|l|}
\hline \multicolumn{2}{|c|}{ General } \\
\hline Code & \multicolumn{1}{|c|}{ Bibliographic data } \\
\hline \multicolumn{2}{|c|}{} \\
\hline \multicolumn{2}{|c|}{ Phase data } \\
\hline Creation method & SHELXL-2016/6 \\
\hline \multicolumn{2}{|c|}{} \\
\hline Formula sum & C36 H20 S \\
\hline Formula weight & $484.58 \mathrm{~g} / \mathrm{mol}$ \\
\hline Crystal system & monoclinic \\
\hline Space-group & $\mathrm{P} 121 / \mathrm{c} 1(14)$ \\
\hline Cell parameters & $\begin{array}{l}\mathrm{a}=12.9908(9) \AA \mathrm{b}=8.3804(6) \AA \\
\mathrm{c}=21.0991(15) \AA \beta=90.996(2)^{\circ}\end{array}$ \\
\hline Cell ratio & $\mathrm{a} / \mathrm{b}=1.5501 \mathrm{~b} / \mathrm{c}=0.3972 \mathrm{c} / \mathrm{a}=1.6242$ \\
\hline Cell volume & $2296.67(30) \AA 3$ \\
\hline
\end{tabular}




\begin{tabular}{|l|l|}
\hline$Z$ & 4 \\
\hline Calc. density & $1.40136 \mathrm{~g} / \mathrm{cm}^{3}$ \\
\hline RAll & 0.0651 \\
\hline RObs & \\
\hline Pearson code & $\mathrm{mP} 228$ \\
\hline Formula type & $\mathrm{NO} 20 \mathrm{P} 36$ \\
\hline Wyckoff sequence & $\mathrm{e} 57$ \\
\hline \multicolumn{2}{|l}{} \\
\hline
\end{tabular}

\section{Me-BPBPT (CCDC)}

\begin{tabular}{|l|l|}
\hline \multicolumn{2}{|l|}{ General } \\
\hline Origin & i17485 \\
\hline Code & \\
\hline \multicolumn{2}{|l|}{} \\
\hline Bibliographic data \\
\hline \multicolumn{2}{|l|}{} \\
\hline Creation method \\
\hline \multicolumn{2}{|l|}{} \\
\hline Phase data \\
\hline \multicolumn{2}{|l|}{} \\
\hline Formula sum & $\mathrm{C} 76 \mathrm{H} 48 \mathrm{~S} 2$ \\
\hline Formula weight & $1025.26 \mathrm{~g} / \mathrm{mol}$ \\
\hline Crystal system & $\mathrm{triclinic}$ \\
\hline Space-group & $\mathrm{P}-1(2)$ \\
\hline Cell parameters & $\mathrm{a}=10.439(2) \AA$ \\
& $\mathrm{b}=15.438(4) \AA$ \\
& $\mathrm{c}=15.996(4) \AA$ \\
& $\alpha=82.840(6)^{\circ}$ \\
& $\beta=80.342(6)^{\circ}$ \\
\hline Cell ratio & $\gamma=86.328(6)^{\circ}$ \\
\hline Cell volume & $\mathrm{a} / \mathrm{b}=0.6762 \mathrm{~b} / \mathrm{c}=0.9651$ \\
\hline Z & $\mathrm{c} / \mathrm{a}=1.5323$ \\
\hline Calc. density & $2519.06(100) \AA^{3}$ \\
\hline Meas. density & 2 \\
\hline Melting point & $1.3516 \mathrm{~g} / \mathrm{cm}^{3}$ \\
\hline RAll & \\
\hline RObs & 0.0586 \\
\hline Pearson code & $\mathrm{aP} 252$ \\
\hline Formula type & $\mathrm{NO} 24 \mathrm{P} 38$ \\
\hline Wyckoff sequence & $\mathrm{i} 126$ \\
\hline
\end{tabular}


Flu-BPBPT (CCDC)

\begin{tabular}{|l|l|}
\hline \multicolumn{2}{|c|}{ General } \\
\hline \multicolumn{2}{|c|}{ Bibliographic data } \\
\hline \multicolumn{2}{|c|}{ Code } \\
\hline \multicolumn{2}{|c|}{ Phase data } \\
\hline \multicolumn{2}{|c|}{} \\
\hline Creation method & SHELXL-2016/6 \\
\hline \multicolumn{2}{|c|}{} \\
\hline \multicolumn{2}{|c|}{} \\
\hline Formula sum & $\mathrm{C} 36 \mathrm{H} 18 \mathrm{~F} 2 \mathrm{~S}$ \\
\hline Formula weight & $520.56 \mathrm{~g} / \mathrm{mol}$ \\
\hline Crystal system & triclinic \\
\hline Space-group & $\mathrm{P}-1(2)$ \\
\hline Cell parameters & $\begin{array}{l}\mathrm{a}=8.0086(4) \AA \mathrm{b}=10.7969(6) \AA \mathrm{c}=13.8874(8) \AA \\
\mathrm{\alpha}=96.808(2)^{\circ} \beta=92.418(2)^{\circ} \gamma=104.746(2)^{\circ}\end{array}$ \\
\hline Cell ratio & $\mathrm{a} / \mathrm{b}=0.7417 \mathrm{~b} / \mathrm{c}=0.7775 \mathrm{c} / \mathrm{a}=1.7341$ \\
\hline Cell volume & $1149.80(11) \AA^{3}$ \\
\hline Z & 2 \\
\hline Calc. density & $1.5035 \mathrm{~g} / \mathrm{cm}^{3}$ \\
\hline RAll & 0.0427 \\
\hline RObs & \\
\hline Pearson code & $\mathrm{aP} 114$ \\
\hline Formula type & $\mathrm{NO} 2 \mathrm{P} 18 \mathrm{Q} 36$ \\
\hline Wyckoff sequence & $\mathrm{i} 57$ \\
\hline
\end{tabular}

\section{Cl-BPBPT (CCDC)}

\begin{tabular}{|l|l|}
\hline \multicolumn{2}{|c|}{ General } \\
\hline Origin & \\
\hline Code & B17313 \\
\hline \multicolumn{2}{|c|}{ Bibliographic data } \\
\hline \multicolumn{2}{|c|}{ Phase data } \\
\hline Creation method & SHELXL-2016/6 \\
\hline \multicolumn{2}{|c|}{} \\
\hline Formula sum & C36 H18 C12 S \\
\hline Formula weight & $553.46 \mathrm{~g} / \mathrm{mol}$ \\
\hline Crystal system & triclinic \\
\hline
\end{tabular}




\begin{tabular}{|l|l|}
\hline Space-group & $\mathrm{P}-1(2)$ \\
\hline Cell parameters & $\begin{array}{l}\mathrm{a}=8.1373(13) \AA \mathrm{b}=11.352(2) \AA \mathrm{c}=14.302(2) \AA \\
\alpha=81.158(5)^{\circ} \beta=89.842(5)^{\circ} \gamma=73.439(4)^{\circ}\end{array}$ \\
\hline Cell ratio & $\mathrm{a} / \mathrm{b}=0.7168 \mathrm{~b} / \mathrm{c}=0.7937 \mathrm{c} / \mathrm{a}=1.7576$ \\
\hline Cell volume & $1250.11(40) \AA^{3}$ \\
\hline Z & 2 \\
\hline Calc. density & $1.47025 \mathrm{~g} / \mathrm{cm}^{3}$ \\
\hline Meas. density & \\
\hline Melting point & \\
\hline RAll & 0.1534 \\
\hline RObs & \\
\hline Pearson code & $\mathrm{aP} 114$ \\
\hline Formula type & $\mathrm{NO} 2 \mathrm{P} 18 \mathrm{Q} 36$ \\
\hline $\begin{array}{l}\text { Wyckoff } \\
\text { sequence }\end{array}$ & $\mathrm{i} 57$ \\
\hline
\end{tabular}

\section{$\underline{\text { PFlu-BPBPT (CCDC) }}$}

\begin{tabular}{|l|l|}
\hline \multicolumn{2}{|c|}{ General } \\
\hline \multicolumn{2}{|c|}{ Origin } \\
\hline \multicolumn{2}{|c|}{$\mathrm{d} 20562 \mathrm{a}$} \\
\hline \multicolumn{2}{|c|}{ Bodeliographic data } \\
\hline \multicolumn{2}{|c|}{ Phase data } \\
\hline Creation method & SHELXL-97 \\
\hline \multicolumn{2}{|c|}{} \\
\hline Formula sum & $\mathrm{C} 36 \mathrm{H} 16 \mathrm{~F} 4 \mathrm{~S}$ \\
\hline Formula weight & $556.55 \mathrm{~g} / \mathrm{mol}$ \\
\hline Crystal system & triclinic \\
\hline Space-group & $\mathrm{P}-1(2)$ \\
\hline Cell parameters & $\mathrm{a}=7.9822(7) \AA \mathrm{b}=11.8140(9) \AA \AA \mathrm{c}=13.1933(15) \AA$ \\
& $\alpha=94.717(3)^{\circ} \beta=97.068(3)^{\circ} \gamma=98.978(2)^{\circ}$ \\
\hline Cell ratio & $\mathrm{a} / \mathrm{b}=0.6757 \mathrm{~b} / \mathrm{c}=0.8955 \mathrm{c} / \mathrm{a}=1.6528$ \\
\hline Cell volume & $1213.02(20) \AA^{3}$ \\
\hline$Z$ & 2 \\
\hline Calc. density & $1.52366 \mathrm{~g} / \mathrm{cm}^{3}$ \\
\hline Meas. density & \\
\hline Melting point & \\
\hline RAll & 0.0745 \\
\hline RObs & \\
\hline
\end{tabular}




\begin{tabular}{|l|l|}
\hline Pearson code & aP114 \\
\hline Formula type & NO4P16Q36 \\
\hline $\begin{array}{l}\text { Wyckoff } \\
\text { sequence }\end{array}$ & i57 \\
\hline
\end{tabular}

11. Computation coordinates for BPBPT, Me-BPBPT, Flu-BPBPT, Cl-BPBPT and PFlu-BPBPT

\section{BPBPT (B3LYP/6-31G**)}

Number of imaginary frequencies $=0$

$\mathrm{HF}=-1782.1723420$ (Hartree)

Cartesian Coordinates (Angstroms)

$\begin{array}{llll}\text { atom } & \mathrm{X} & \mathrm{Y} & \mathrm{Z}\end{array}$

S $\quad-0.00001047-2.20427997 \quad-0.00016730$

C $\quad-1.24369040 \quad-0.97228600 \quad 0.11718479$

C $\quad-2.64689186-1.25153763 \quad 0.12641345$

C $\quad-3.13847598 \quad-2.58953532 \quad 0.02724340$

$\mathrm{H} \quad-2.43118388 \quad-3.41333110 \quad 0.03929106$

$\begin{array}{lllll}\text { C } & -4.47415170 & -2.84079985 & -0.07008681\end{array}$

$\mathrm{H} \quad-4.84187241 \quad-3.86210189-0.11513886$

$\begin{array}{lllll}\text { C } & -5.40725717 & -1.76883920 & -0.19393367\end{array}$

C $\quad-6.77430600 \quad-2.03272221 \quad-0.45262026$

$\mathrm{H} \quad-7.10465474 \quad-3.06787599 \quad-0.47786020$

C $\quad \begin{array}{llll}-7.66349290 & -1.00977606 & -0.70254417\end{array}$

$\mathrm{H} \quad\left[\begin{array}{llll}\mathrm{C} & -8.70716665 & -1.22624409 & -0.90947139\end{array}\right.$

$\begin{array}{lllll}\text { C } & -7.19495757 & 0.31856777 & -0.73401976\end{array}$

$\mathrm{H} \quad \begin{array}{llll}\mathrm{H} & -7.87259930 & 1.12484242 & -0.99903734\end{array}$

$\begin{array}{lllll}\text { C } & -5.87374697 & 0.60580350 & -0.45258023\end{array}$

$\mathrm{H} \quad-5.53334958 \quad 1.62933600 \quad-0.53862876$

C $\quad-4.94203428 \quad-0.41507143 \quad-0.11971723$

$\begin{array}{lllll}\text { C } & -3.54711529 & -0.16268681 & 0.19033160\end{array}$

$\begin{array}{llll}\text { C } & -3.01541953 & 1.13005670 & 0.61316313\end{array}$ 


$\begin{array}{llll}\mathrm{C} & -3.83604159 & 2.10941799 & 1.22766674 \\ \mathrm{H} & -4.88664601 & 1.89927654 & 1.37523678 \\ \mathrm{C} & -3.32157620 & 3.29102056 & 1.72777081 \\ \mathrm{H} & -3.98291744 & 4.00566922 & 2.20850634 \\ \mathrm{C} & -1.94217117 & 3.53515827 & 1.66295335 \\ \mathrm{H} & -1.52440492 & 4.44394279 & 2.08581156 \\ \mathrm{C} & -1.10426772 & 2.58501719 & 1.11101358 \\ \mathrm{H} & -0.03430181 & 2.74451706 & 1.14015986 \\ \mathrm{C} & -1.60366116 & 1.37858178 & 0.56621956 \\ \mathrm{C} & -0.71600632 & 0.31584063 & 0.12997532 \\ \mathrm{C} & 0.71602847 & 0.31583669 & -0.13014309 \\ \mathrm{C} & 1.60370689 & 1.37858662 & -0.56631568 \\ \mathrm{C} & 1.10435367 & 2.58505270 & -1.11108350 \\ \mathrm{H} & 0.03439188 & 2.74458212 & -1.14023135 \\ \mathrm{C} & 1.94228802 & 3.53518372 & -1.66299322 \\ \mathrm{H} & 1.52455179 & 4.44398694 & -2.08584065 \\ \mathrm{C} & 3.32168975 & 3.29101872 & -1.72779669 \\ \mathrm{H} & 3.98304898 & 4.00566066 & -2.20851732 \\ \mathrm{C} & 3.83612159 & 2.10939977 & -1.22769859 \\ \mathrm{H} & 4.88672613 & 1.89922887 & -1.37524183 \\ \mathrm{C} & 3.01546619 & 1.13004185 & -0.61323619 \\ \mathrm{C} & 3.54712622 & -0.16271549 & -0.19043084 \\ \mathrm{C} & 4.94201247 & -0.41510372 & 0.11977625 \\ \mathrm{C} & 5.87368294 & 0.60577632 & 0.45273366 \\ \mathrm{H} & 5.53330391 & 1.62932432 & 0.53864933 \\ \mathrm{C} & 7.19484300 & 0.31853235 & 0.73440661 \\ \mathrm{H} & 7.87245616 & 1.12481260 & 0.99948044 \\ \mathrm{C} & 7.66336241 & -1.00981820 & 0.70308175 \\ \mathrm{H} & 8.70698895 & -1.22629575 & 0.91023842 \\ \mathrm{H} & 7.77420985 & -2.03276434 & 0.45302676 \\ \mathrm{H} & & & \\ \mathrm{H} & & -3.06791902 & 0.47834703\end{array}$




$\begin{array}{llll}\mathrm{C} & 5.40721510 & -1.76887138 & 0.19407711 \\ \mathrm{C} & 4.47413262 & -2.84083222 & 0.07002080 \\ \mathrm{H} & 4.84185602 & -3.86213335 & 0.11506425 \\ \mathrm{C} & 3.13847346 & -2.58956925 & -0.02750913 \\ \mathrm{H} & 2.43118206 & -3.41336371 & -0.03976332 \\ \mathrm{C} & 2.64689339 & -1.25156393 & -0.12663565 \\ \mathrm{C} & 1.24369281 & -0.97230595 & -0.11744349\end{array}$

\section{Me-BPBPT (B3LYP/6-31G**)}

Number of imaginary frequencies $=0$

$\mathrm{HF}=-1860.8140754$ (Hartree)

Cartesian Coordinates (Angstroms)

$\begin{array}{cccc}\text { atom } & \mathrm{X} & \mathrm{Y} & \mathrm{Z} \\ \mathrm{S} & -0.00000645 & -2.47271433 & -0.00004090 \\ \mathrm{C} & 1.24722154 & -1.24020923 & -0.07107138 \\ \mathrm{C} & 2.64974931 & -1.51780506 & -0.03009304 \\ \mathrm{C} & 3.13826524 & -2.85601347 & 0.08333778 \\ \mathrm{H} & 2.43186813 & -3.67972461 & 0.04348966 \\ \mathrm{C} & 4.46949104 & -3.10764288 & 0.22771843 \\ \mathrm{H} & 4.83554656 & -4.12903367 & 0.28334679 \\ \mathrm{C} & 5.39727101 & -2.03581191 & 0.38817362 \\ \mathrm{C} & 6.75372878 & -2.30028985 & 0.69705582 \\ \mathrm{H} & 7.08290878 & -3.33556299 & 0.73187238 \\ \mathrm{C} & 7.63288614 & -1.27810535 & 0.98317479 \\ \mathrm{H} & 8.66809130 & -1.49513377 & 1.22857903 \\ \mathrm{C} & 7.16305892 & 0.05000939 & 1.00088251 \\ \mathrm{H} & 7.83003297 & 0.85567834 & 1.29353568 \\ \mathrm{C} & 5.85327040 & 0.33774870 & 0.67064133 \\ \mathrm{H} & 5.50934848 & 1.36087801 & 0.74606381 \\ \mathrm{C} & 4.93469693 & -0.68198173 & 0.30000942 \\ \mathrm{C} & 3.55184327 & -0.42832993 & -0.06021274\end{array}$




\begin{tabular}{|c|c|c|c|}
\hline $\mathrm{C}$ & 3.03513737 & 0.86509875 & -0.49918499 \\
\hline $\mathrm{C}$ & 3.87778090 & 1.84657696 & -1.08077307 \\
\hline $\mathrm{H}$ & 4.93286160 & 1.63066570 & -1.18821059 \\
\hline $\mathrm{C}$ & 3.40311284 & 3.03875133 & -1.60411798 \\
\hline $\mathrm{C}$ & 2.01301050 & 3.26741132 & -1.57930752 \\
\hline $\mathrm{H}$ & 1.60849805 & 4.17669732 & -2.01691138 \\
\hline $\mathrm{C}$ & 1.15264309 & 2.32124655 & -1.06208011 \\
\hline $\mathrm{H}$ & 0.08547784 & 2.48710660 & -1.13287894 \\
\hline $\mathrm{C}$ & 1.62426866 & 1.11082839 & -0.50106405 \\
\hline $\mathrm{C}$ & 0.72040274 & 0.04815098 & -0.10304319 \\
\hline $\mathrm{C}$ & -0.72040025 & 0.04816066 & 0.10290101 \\
\hline $\mathrm{C}$ & -1.62424210 & 1.11084651 & 0.50094765 \\
\hline $\mathrm{C}$ & -1.15260026 & 2.32127924 & 1.06191155 \\
\hline $\mathrm{H}$ & -0.08543548 & 2.48716520 & 1.13264608 \\
\hline $\mathrm{C}$ & -2.01294440 & 3.26743805 & 1.57919513 \\
\hline $\mathrm{H}$ & -1.60840284 & 4.17673554 & 2.01674815 \\
\hline $\mathrm{C}$ & -3.40303771 & 3.03875611 & 1.60412701 \\
\hline $\mathrm{C}$ & -3.87772374 & 1.84656812 & 1.08082420 \\
\hline $\mathrm{H}$ & -4.93278786 & 1.63062581 & 1.18836490 \\
\hline $\mathrm{C}$ & -3.03511686 & 0.86510981 & 0.49915775 \\
\hline $\mathrm{C}$ & -3.55184642 & -0.42830699 & 0.06018909 \\
\hline $\mathrm{C}$ & -4.93472544 & -0.68195008 & -0.29995167 \\
\hline $\mathrm{C}$ & -5.85333798 & 0.33778265 & -0.67048494 \\
\hline $\mathrm{H}$ & -5.50943341 & 1.36091705 & -0.74590992 \\
\hline $\mathrm{C}$ & -7.16315036 & 0.05004444 & -1.00062931 \\
\hline $\mathrm{H}$ & -7.83014966 & 0.85571811 & -1.29321203 \\
\hline $\mathrm{C}$ & -7.63297229 & -1.27807317 & -0.98291779 \\
\hline $\mathrm{H}$ & -8.66819851 & -1.49509819 & -1.22823622 \\
\hline $\mathrm{C}$ & -6.75378472 & -2.30025824 & -0.69690043 \\
\hline $\mathrm{H}$ & -7.08295683 & -3.33553400 & -0.73171721 \\
\hline $\mathrm{C}$ & -5.39730112 & -2.03577952 & -0.38812378 \\
\hline
\end{tabular}




$\begin{array}{lrrr}\mathrm{C} & -4.46950561 & -3.10761441 & -0.22779420 \\ \mathrm{H} & -4.83556017 & -4.12900350 & -0.28346281 \\ \mathrm{C} & -3.13827123 & -2.85598768 & -0.08348789 \\ \mathrm{H} & -2.43186802 & -3.67969867 & -0.04375547 \\ \mathrm{C} & -2.64975686 & -1.51778405 & 0.02999333 \\ \mathrm{C} & -1.24722803 & -1.24019800 & 0.07094679 \\ \mathrm{C} & 4.33584148 & 4.05057778 & -2.22455936 \\ \mathrm{H} & 4.01445004 & 4.32269113 & -3.23619981 \\ \mathrm{H} & 4.36315469 & 4.97711404 & -1.63810217 \\ \mathrm{H} & 5.35800326 & 3.66778788 & -2.28788327 \\ \mathrm{C} & -4.33574247 & 4.05056885 & 2.22462379 \\ \mathrm{H} & -4.36328188 & 4.97701818 & 1.63803739 \\ \mathrm{H} & -5.35785022 & 3.66767834 & 2.28821372 \\ \mathrm{H} & -4.01416718 & 4.32286340 & 3.23615536\end{array}$

\section{Flu-BPBPT (B3LYP/6-31G**)}

Number of imaginary frequencies $=0$

\begin{tabular}{lccc}
\multicolumn{4}{l}{$\mathrm{HF}=-1980.6354429$} \\
Cartesian & Coordinates (Angstroms) & \\
atom & $\mathrm{X}$ & $\mathrm{Y}$ & $\mathrm{Z}$ \\
$\mathrm{S}$ & -0.00001161 & -2.45441735 & -0.00005149 \\
$\mathrm{~F}$ & -4.19715261 & 3.93971889 & 2.12842832 \\
$\mathrm{~F}$ & 4.19735160 & 3.93974152 & -2.12823152 \\
$\mathrm{C}$ & -1.24644093 & -1.22227654 & 0.07607064 \\
$\mathrm{C}$ & -2.64936319 & -1.50012754 & 0.04056850 \\
$\mathrm{C}$ & -3.13657837 & -2.83935312 & -0.06479352 \\
$\mathrm{H}$ & -2.42933986 & -3.66222388 & -0.02556645 \\
$\mathrm{C}$ & -4.46844709 & -3.09245311 & -0.19960103 \\
$\mathrm{H}$ & -4.83351875 & -4.11452118 & -0.24794004 \\
$\mathrm{C}$ & -5.39934883 & -2.02305488 & -0.35719104 \\
$\mathrm{C}$ & -6.75793093 & -2.29212567 & -0.65181197
\end{tabular}




\begin{tabular}{|c|c|c|c|}
\hline $\mathrm{H}$ & -7.08505359 & -3.32818545 & -0.67895701 \\
\hline $\mathrm{C}$ & -7.64208059 & -1.27293364 & -0.93294049 \\
\hline $\mathrm{H}$ & -8.67928530 & -1.49286091 & -1.16656010 \\
\hline $\mathrm{C}$ & -7.17526762 & 0.05589243 & -0.96077362 \\
\hline $\mathrm{H}$ & -7.84676095 & 0.85910801 & -1.24930602 \\
\hline $\mathrm{C}$ & -5.86285343 & 0.34825488 & -0.64513820 \\
\hline $\mathrm{H}$ & -5.52382899 & 1.37205227 & -0.73169459 \\
\hline $\mathrm{C}$ & -4.93860373 & -0.66803954 & -0.27980369 \\
\hline $\mathrm{C}$ & -3.55309368 & -0.41234970 & 0.06808252 \\
\hline $\mathrm{C}$ & -3.03564879 & 0.88282898 & 0.50091706 \\
\hline $\mathrm{C}$ & -3.88174101 & 1.86597992 & 1.07062825 \\
\hline $\mathrm{H}$ & -4.94129009 & 1.69182942 & 1.19048361 \\
\hline $\mathrm{C}$ & -3.36014560 & 3.03464660 & 1.57631629 \\
\hline $\mathrm{C}$ & -1.98899655 & 3.29574087 & 1.58588885 \\
\hline $\mathrm{H}$ & -1.61327319 & 4.20908180 & 2.03329551 \\
\hline $\mathrm{C}$ & -1.14114135 & 2.33576163 & 1.06817095 \\
\hline $\mathrm{H}$ & -0.07312362 & 2.49321053 & 1.14044780 \\
\hline $\mathrm{C}$ & -1.62205930 & 1.12998649 & 0.50490562 \\
\hline $\mathrm{C}$ & -0.71965891 & 0.06575530 & 0.10580027 \\
\hline $\mathrm{C}$ & 0.71963935 & 0.06573477 & -0.10606780 \\
\hline $\mathrm{C}$ & 1.62209533 & 1.12995006 & -0.50514228 \\
\hline $\mathrm{C}$ & 1.14120252 & 2.33565084 & -1.06859157 \\
\hline $\mathrm{H}$ & 0.07318446 & 2.49300457 & -1.14108059 \\
\hline $\mathrm{C}$ & 1.98911128 & 3.29564835 & -1.58618583 \\
\hline $\mathrm{H}$ & 1.61345304 & 4.20894199 & -2.03374388 \\
\hline $\mathrm{C}$ & 3.36027269 & 3.03462564 & -1.57629162 \\
\hline $\mathrm{C}$ & 3.88183508 & 1.86600550 & -1.07045909 \\
\hline $\mathrm{H}$ & 4.94142287 & 1.69193874 & -1.19007905 \\
\hline $\mathrm{C}$ & 3.03566392 & 0.88282789 & -0.50090272 \\
\hline $\mathrm{C}$ & 3.55307385 & -0.41237843 & -0.06802043 \\
\hline $\mathrm{C}$ & 4.93853764 & -0.66808958 & 0.27995677 \\
\hline
\end{tabular}




$\begin{array}{llll}\mathrm{C} & 5.86274516 & 0.34819131 & 0.64545245 \\ \mathrm{H} & 5.52366701 & 1.37196396 & 0.73211028 \\ \mathrm{C} & 7.17513930 & 0.05582377 & 0.96115183 \\ \mathrm{H} & 7.84660717 & 0.85901765 & 1.24980357 \\ \mathrm{C} & 7.64197481 & -1.27299712 & 0.93322409 \\ \mathrm{H} & 8.67916968 & -1.49292558 & 1.16688658 \\ \mathrm{C} & 6.75786494 & -2.29217918 & 0.65194671 \\ \mathrm{H} & 7.08500554 & -3.32823527 & 0.67903171 \\ \mathrm{C} & 5.39929448 & -2.02311164 & 0.35725921 \\ \mathrm{C} & 4.46841399 & -3.09249201 & 0.19948998 \\ \mathrm{H} & 4.83347435 & -4.11456845 & 0.24773839 \\ \mathrm{C} & 3.13654841 & -2.83938182 & 0.06460592 \\ \mathrm{H} & 2.42932690 & -3.66225856 & 0.02518900 \\ \mathrm{C} & 2.64933630 & -1.50015540 & -0.04065921 \\ \mathrm{C} & 1.24641055 & -1.22227890 & -0.07622950\end{array}$

\section{Cl-BPBPT (B3LYP/6-31G**)}

Number of imaginary frequencies $=0$

$\mathrm{HF}=-2701.3610886$ (Hartree)

Cartesian Coordinates (Angstroms)

$\begin{array}{cccc}\text { atom } & \mathrm{X} & \mathrm{Y} & \mathrm{Z} \\ \mathrm{S} & -0.00005835 & -2.70815100 & -0.00029670 \\ \mathrm{Cl} & 4.54769728 & 3.95857548 & -2.13765893 \\ \mathrm{Cl} & -4.54724567 & 3.95862618 & 2.13795556 \\ \mathrm{C} & -1.24880969 & -1.47685122 & 0.02875822 \\ \mathrm{C} & -2.64926082 & -1.75606487 & -0.05928698 \\ \mathrm{C} & -3.13212623 & -3.09508690 & -0.18411915 \\ \mathrm{H} & -2.42747001 & -3.91842332 & -0.11797323 \\ \mathrm{C} & -4.45801809 & -3.34690523 & -0.37090693 \\ \mathrm{H} & -4.82165536 & -4.36863110 & -0.43394193 \\ \mathrm{C} & -5.38131272 & -2.27682490 & -0.56479576\end{array}$




\begin{tabular}{|c|c|c|c|}
\hline $\mathrm{C}$ & -6.72730791 & -2.54462428 & -0.91317274 \\
\hline $\mathrm{H}$ & -7.05417059 & -3.58027064 & -0.95384672 \\
\hline $\mathrm{C}$ & -7.59850792 & -1.52429199 & -1.22862830 \\
\hline $\mathrm{H}$ & -8.62579173 & -1.74321796 & -1.50327560 \\
\hline $\mathrm{C}$ & -7.13022718 & -0.19569326 & -1.23755657 \\
\hline $\mathrm{H}$ & -7.78925976 & 0.60807597 & -1.55181873 \\
\hline $\mathrm{C}$ & -5.83110560 & 0.09555448 & -0.87038108 \\
\hline $\mathrm{H}$ & -5.48835401 & 1.11931929 & -0.94302053 \\
\hline $\mathrm{C}$ & -4.92343716 & -0.92205503 & -0.46899416 \\
\hline $\mathrm{C}$ & -3.55297336 & -0.66817620 & -0.06579975 \\
\hline $\mathrm{C}$ & -3.05082578 & 0.62593668 & 0.38806764 \\
\hline $\mathrm{C}$ & -3.91967902 & 1.60450911 & 0.93160506 \\
\hline $\mathrm{H}$ & -4.97901482 & 1.40732532 & 1.00572923 \\
\hline $\mathrm{C}$ & -3.42907660 & 2.78251051 & 1.45707207 \\
\hline $\mathrm{C}$ & -2.05338416 & 3.03958129 & 1.50744837 \\
\hline $\mathrm{H}$ & -1.68127562 & 3.95175725 & 1.95946584 \\
\hline $\mathrm{C}$ & -1.18467083 & 2.08201617 & 1.02211338 \\
\hline $\mathrm{H}$ & -0.12077798 & 2.24559004 & 1.13327977 \\
\hline $\mathrm{C}$ & -1.63985598 & 0.87404032 & 0.44406974 \\
\hline $\mathrm{C}$ & -0.72320912 & -0.18854922 & 0.07775222 \\
\hline $\mathrm{C}$ & 0.72314818 & -0.18858162 & -0.07831895 \\
\hline $\mathrm{C}$ & 1.63990146 & 0.87397393 & -0.44453465 \\
\hline $\mathrm{C}$ & 1.18484477 & 2.08193308 & -1.02272180 \\
\hline $\mathrm{H}$ & 0.12098253 & 2.24547108 & -1.13418535 \\
\hline $\mathrm{C}$ & 2.05367555 & 3.03949762 & -1.50784567 \\
\hline $\mathrm{H}$ & 1.68169191 & 3.95166030 & -1.95999304 \\
\hline $\mathrm{C}$ & 3.42935093 & 2.78242800 & -1.45710182 \\
\hline $\mathrm{C}$ & 3.91983212 & 1.60443317 & -0.93150508 \\
\hline $\mathrm{H}$ & 4.97919015 & 1.40728363 & -1.00535239 \\
\hline $\mathrm{C}$ & 3.05084267 & 0.62586250 & -0.3881726 \\
\hline $\mathrm{C}$ & 3.55288855 & -0.66826862 & 0.0658409 \\
\hline
\end{tabular}




$\begin{array}{llll}\mathrm{C} & 4.92327875 & -0.92219672 & 0.46922789 \\ \mathrm{C} & 5.83089811 & 0.09536857 & 0.87084714 \\ \mathrm{H} & 5.48810318 & 1.11911001 & 0.94360836 \\ \mathrm{C} & 7.12997947 & -0.19591502 & 1.23813016 \\ \mathrm{H} & 7.78897660 & 0.60781506 & 1.55256665 \\ \mathrm{C} & 7.59826397 & -1.52451426 & 1.22909733 \\ \mathrm{H} & 8.62552709 & -1.74346612 & 1.50380132 \\ \mathrm{C} & 6.72709143 & -2.54481506 & 0.91347367 \\ \mathrm{H} & 7.05394559 & -3.58046640 & 0.95410012 \\ \mathrm{C} & 5.38112555 & -2.27698291 & 0.56499973 \\ \mathrm{C} & 4.45782855 & -3.34702652 & 0.37096543 \\ \mathrm{H} & 4.82142369 & -4.36876795 & 0.43399419 \\ \mathrm{C} & 3.13196010 & -3.09516513 & 0.18404500 \\ \mathrm{H} & 2.42730060 & -3.91848855 & 0.11776570 \\ \mathrm{C} & 2.64914505 & -1.75613321 & 0.05920157 \\ \mathrm{C} & 1.24871378 & -1.47687126 & -0.02907337\end{array}$

\section{PFlu-BPBPT (B3LYP/6-31G**)}

Number of imaginary frequencies $=0$

$\mathrm{HF}=-2179.0849063$ (Hartree)

Cartesian Coordinates (Angstroms)

$\begin{array}{cccc}\text { atom } & \mathrm{X} & \mathrm{Y} & \mathrm{Z} \\ \mathrm{C} & 1.24822454 & -1.47048796 & -0.05726410 \\ \mathrm{C} & 2.64983690 & -1.75042498 & -0.00573839 \\ \mathrm{C} & 3.13542438 & -3.08975028 & 0.10497297 \\ \mathrm{H} & 2.42844270 & -3.91251540 & 0.05952459 \\ \mathrm{C} & 4.46599112 & -3.34297163 & 0.25158233 \\ \mathrm{H} & 4.83060722 & -4.36495075 & 0.30328389 \\ \mathrm{C} & 5.39539206 & -2.27335511 & 0.41779771 \\ \mathrm{C} & 6.75143554 & -2.54203410 & 0.72412506 \\ \mathrm{H} & 7.07891524 & -3.57787796 & 0.75308121\end{array}$




$\begin{array}{llll}\mathrm{C} & 7.63259165 & -1.52269378 & 1.01422698 \\ \mathrm{H} & 8.66770050 & -1.74258023 & 1.25681435 \\ \mathrm{C} & 7.16528850 & -0.19403423 & 1.04029029 \\ \mathrm{H} & 7.83365392 & 0.60878445 & 1.33684520 \\ \mathrm{C} & 5.85553978 & 0.09804771 & 0.71345520 \\ \mathrm{H} & 5.51496215 & 1.12137229 & 0.80123600 \\ \mathrm{C} & 4.93559651 & -0.91828866 & 0.33790550 \\ \mathrm{C} & 3.55375430 & -0.66266627 & -0.02417996 \\ \mathrm{C} & 3.04123510 & 0.63181400 & -0.46102227 \\ \mathrm{C} & 3.89464400 & 1.61381049 & -1.02501547 \\ \mathrm{H} & 4.95535918 & 1.43725341 & -1.13247185 \\ \mathrm{C} & 3.39709002 & 2.78638179 & -1.54019630 \\ \mathrm{C} & 2.01780378 & 3.02789671 & -1.54733815 \\ \mathrm{C} & 1.15063288 & 2.08678147 & -1.04710153 \\ \mathrm{H} & 0.09002672 & 2.27390714 & -1.14456675 \\ \mathrm{C} & 1.62842138 & 0.88020854 & -0.48264900 \\ \mathrm{C} & 0.72118965 & -0.18235110 & -0.09441601 \\ \mathrm{C} & -0.72118839 & -0.18235141 & 0.09441501 \\ \mathrm{C} & -1.62842050 & 0.88020749 & 0.48264901 \\ \mathrm{C} & -1.15063361 & 2.08678062 & 1.04710226 \\ \mathrm{H} & -0.09002780 & 2.27390764 & 1.14456908 \\ \mathrm{C} & -2.01780603 & 3.02789505 & 1.54733810 \\ \mathrm{C} & -3.39709210 & 2.78637905 & 1.54019521 \\ \mathrm{C} & -3.89464461 & 1.61380755 & 1.02501335 \\ \mathrm{H} & -4.95535990 & 1.43724948 & 1.13246762 \\ \mathrm{C} & -3.04123401 & 0.63181216 & 0.46102104 \\ \mathrm{C} & -3.55375242 & -0.66266774 & 0.02417776 \\ \mathrm{C} & -2.64983501 & -1.75042622 & 0.00573328 \\ & -1.24822283 & -1.47048827 & 0.05725940 \\ \mathrm{C} & -3.13542255 & -3.08975129 & -0.10497880 \\ -2.42844084 & -3.91251662 & -0.05953506\end{array}$




$\begin{array}{llll}\text { C } & -4.46598979 & -3.34297253 & -0.25158485 \\ \text { H } & -4.83060609 & -4.36495165 & -0.30328529 \\ \text { C } & -5.39539132 & -2.27335585 & -0.41779614 \\ \text { C } & -4.93559555 & -0.91828977 & -0.33790425 \\ \text { C } & -5.85553925 & 0.09804767 & -0.71344992 \\ \text { H } & -5.51496151 & 1.12137251 & -0.80122799 \\ \text { C } & -7.16528866 & -0.19403362 & -1.04028251 \\ \text { H } & -7.83365477 & 0.60878522 & -1.33683551 \\ \text { C } & -7.63259197 & -1.52269329 & -1.01421962 \\ \text { H } & -8.66770161 & -1.74257890 & -1.25680459 \\ \text { C } & -6.75143586 & -2.54203424 & -0.72412032 \\ \text { H } & -7.07891609 & -3.57787796 & -0.75307537 \\ \text { F } & 4.21919195 & 3.69446654 & -2.09404246 \\ \text { F } & 1.55789366 & 4.16250195 & -2.09908986 \\ \text { F } & -1.55789715 & 4.16250028 & 2.09909097 \\ \text { F } & -4.21919512 & 3.69446279 & 2.09404133 \\ \text { S } & 0.00000094 & -2.70141590 & -0.00000230\end{array}$

